Summer 8-2021

\title{
Exploring Occupational Dysfunction and Occupational Performance for Youth in Homeless Shelters
}

\author{
Akio Ross \\ University of St. Augustine for Health Sciences \\ DOI: https://doi.org/10.46409/sr.NAGB6535
}

Follow this and additional works at: https://soar.usa.edu/capstones

Part of the Occupational Therapy Commons, and the Social Work Commons

\begin{abstract}
Recommended Citation
Ross, A. (2021). Exploring Occupational Dysfunction and Occupational Performance for Youth in Homeless Shelters. [Doctoral project, University of St Augustine for Health Sciences]. SOAR @ USA: Student Capstone Projects Collection. https://doi.org/10.46409/sr.NAGB6535
\end{abstract}

This Capstone is brought to you for free and open access by the Student Research at SOAR @ USA. It has been accepted for inclusion in Student Capstone Projects by an authorized administrator of SOAR @ USA. For more information, please contact soar@usa.edu, erobinson@usa.edu. 


\title{
Exploring Occupational Dysfunction and Occupational Performance for Youth in Homeless Shelters
}

\author{
Akio, O, Ross \\ Department of Occupational Therapy, University of St. Augustine for Health Sciences
}

A Capstone Presented in Partial Fulfillment

of the Requirement for the Degree of DOCTOR OF OCCUPATIONAL THERAPY

University of St. Augustine for Health Sciences

August, 2021 


\title{
Exploring the Role of Occupational Therapy in Homeless Youth Shelters
}

\author{
Akio, O, Ross \\ Department of Occupational Therapy, University of St. Augustine for Health Sciences \\ has been approved
}

August, 2021

APPROVED:

Pamela Kasyan-Howe, OTD, OTR/L, Doctoral Coordinator

Kristin Domville, DrOT, OTR/L, Doctoral Coordinator

Lisa Schubert, OTD, OTR/L, Doctoral Coordinator

Jose Rafols, OTD, OTR/L, Program Director

ACCEPTED AND SIGNED:

Pamela Kasyan-Howe, OTD, OTR/L, Doctoral Coordinator

Kristin Domville, Dr.OT, OTR/L, Doctoral Coordinator

Lisa Schubert, OTD, OTR/L, Doctoral Coordinator

Jose Rafols, OTD, OTR/L, Program Director 
Table of Contents

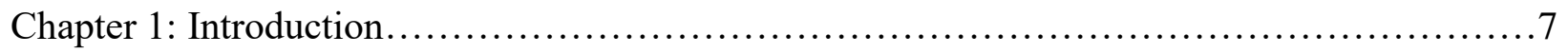

Background..........................................................

Statement of the Problem................................................... 10

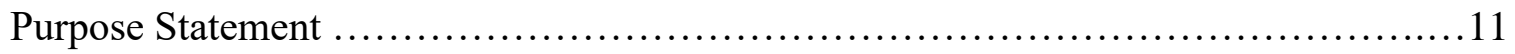

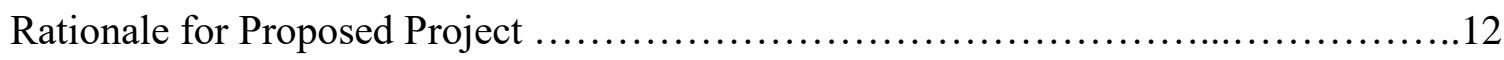

Significance for Proposed Project............................................ 13

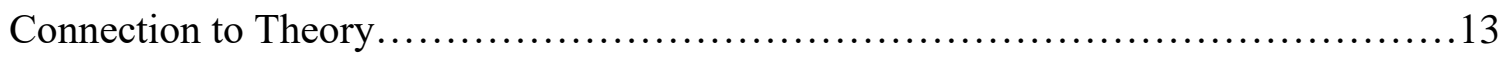

Learning Objectives..................................................... 14

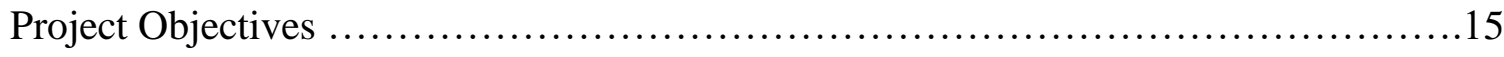

Definition of Terms.................................................... 17

Assumptions............................................................. 17

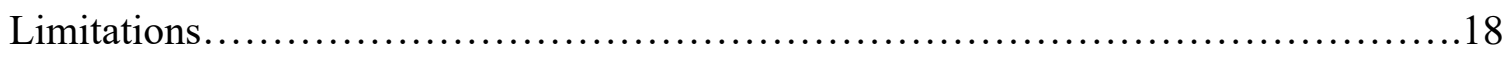

Delimitations............................................................ 18

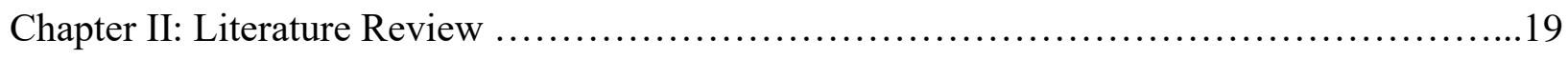

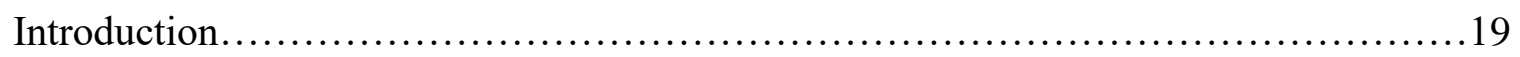

Youth Affected by Homelessness............................................20

Challenges and Health Disparities for Youth Affected by Homelessness.................21

Current Services for Youth Effected by Homelessness............................24

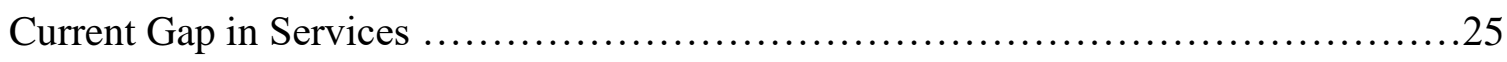

OT Role Serving Youth Affected by Homelessness ...............................27

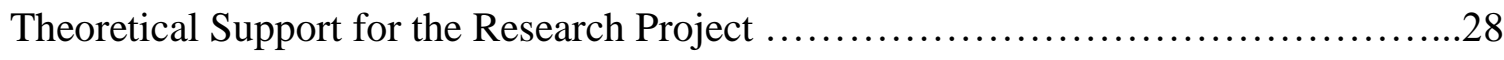


Conclusion .29

Chapter III: Project Description.................................................. 31

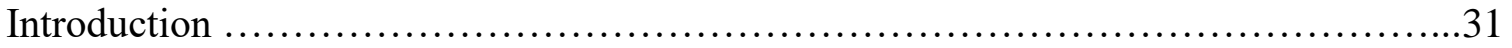

Objectives........................................................... 31

Learning Objectives:..............................................31

Project Objectives:................................................... 32

Process \& Methods ..............................................................

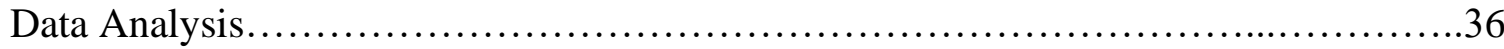

Conceptual Framework.................................................... 37

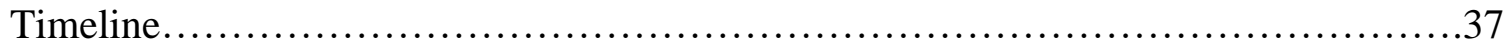

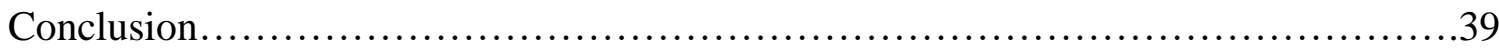

Chapter IV: Results and Analysis ..............................................40

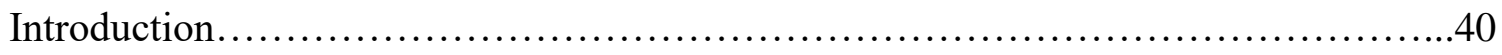

Data Collection........................................................41

Project Objectives and Deliverables .......................................42

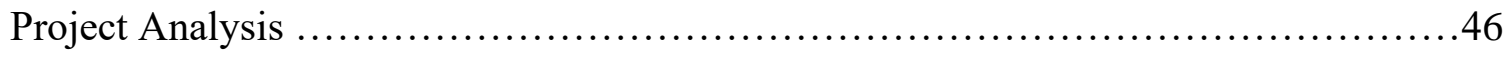

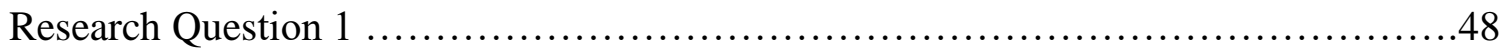

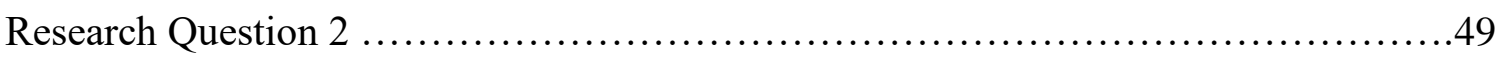

Conclusions..........................................................50

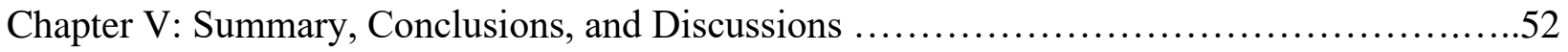

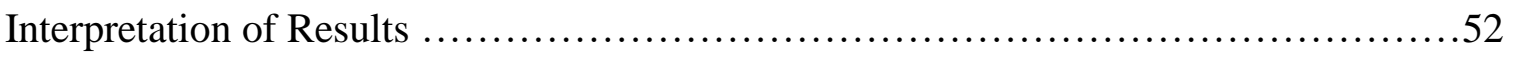

Research Question One...................................................53 


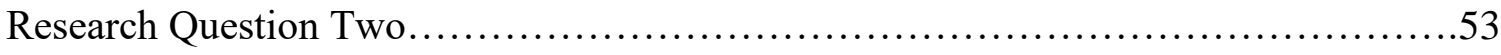

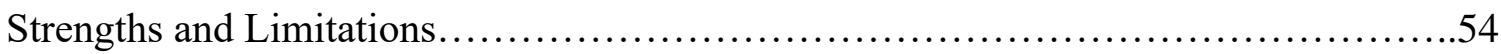

Recommendations for the Future...............................................5

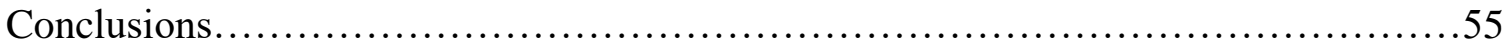

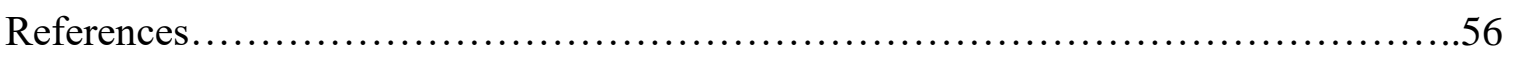

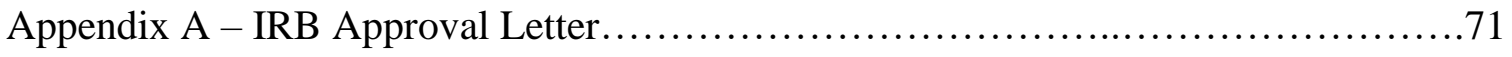

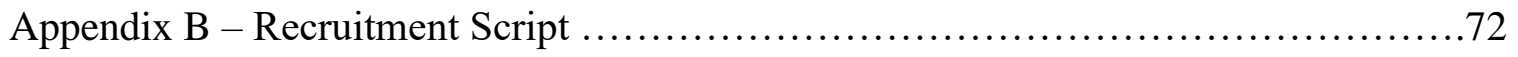

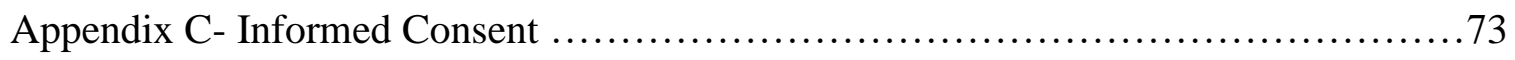

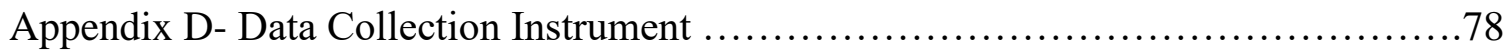

Appendix E - Conceptual Framework............................................... 81 
Copyright $\odot$ Name, year all rights reserved. 


\section{Exploring the Role of Occupational Therapy in Homeless Youth Shelters}

\section{Chapter I: Introduction}

The capstone project aims to explore and identify the role of occupational therapist in homeless youth shelters, to improve life skills necessary for independent living, and transition into the community of youths that occupy youth shelters. The proposed research project will fill the gap between occupational therapist, and youth shelters, by revealing barriers, while simultaneously developing and identifying a role for occupational therapist in homeless youth shelters.

\section{Background}

There is a limited presence of occupational therapy (OT) representation in homeless youth shelters. According to The American Occupational Therapy Association (AOTA) fact sheet $2 \%$ of OT's work in community settings, which includes homeless shelters (date). AOTA does not indicate what settings are included in the $2 \%$ of the OT's working in the community indicating even less work in homeless youth shelters. There are approximately 4.2 million youths aged 13-25 affected by homelessness every year in which 700,000 are unaccompanied minors ages 13-17, without a parent or legal guardian (McCann, 2019). This accounts for 1 in 30 adolescents ages 13-17 that experience some form of homelessness in a year (US Department of Housing and Urban Development, 2019).

Youth homelessness is defined as a young person who is under the age of 25 who lacks a stable living situation in the present and near future, including individuals who live in a place not meant for human habitation, such as the streets or in their car, emergency shelter, transitional housing, or hotel paid for by a government or charitable organization (Federal Definitions, 2011). The homeless youth populace are at a high risk for factors such as unemployment, low 
educational attainment, early parenthood, criminal activity, and mental health conditions (Daining \& DePanfilis, 2007). Without adequate support, an estimated 50\% of transition-age homeless youth continue experiencing housing instability and/or homelessness into adulthood (Winiarski et al., 2020). Life skills that would be taught by a youth caretaker, allowing an individual to have an equitable chance to become a functioning member of society are not developed at the same rate as youth who have experienced homelessness. For example, between the ages of 10-13 a child should learn how to change their own bed sheets, use a washing machine and dryer, plan and prepare a meal with several ingredients, read labels, iron clothes, and use basic tools (Hutton, 2018). While youth between the ages of 14 to 18 should be able to perform more sophisticated cleaning and maintenance chores, fill a car with gas, read and understand medicine labels, and interview for and get a job . According to World Health Organization (WHO) (2020), life skills are defined as "abilities for adaptive and positive behavior that enable individuals to deal effectively with the demands and challenges of everyday life" ( para. 2). The WHO has five main life skills areas: decision-making and problemsolving, creative, and critical thinking, communication and interpersonal skills, self-awareness and empathy, and coping with emotions and stress.

Homeless youth face mental health concerns because of traumatic experiences, before and/or during homelessness (Davies et al., 2017). Mental health issues can include anxiety, mood disorders, phobias, panic disorders, obsessive compulsive disorder, Post traumatic stress disorder (PTSD), impulse control disorders, suicidal thoughts, psychosis, depression, attention deficit hyperactive disorder (ADHD), eating disorders, alcohol and/or drug abuse or drug dependence (Hodgson et al., 2013). In a mental health assessment of 60 homeless youth, 48\% of the youth were clinically symptomatic and most youth accessed a range of general health services (Hughes 
et al., 2010). Mental wellness is critical for stable employment and the formation of reliable and safe interpersonal connections; thus, mental health problems can play a direct role in perpetuating the cycle of homelessness (Winiarski et al., 2020).

There are federal services that come to the aid of homeless youth by providing shelter, clothing, and meals. These programs include Basic Center Programs which helps to create and strengthen community-based programs that meet the immediate needs of runaway and homeless youth under 18 for up to 21 days (cite). Transitional Living Programs provide stable living accommodations, educational opportunities, job attainment services, mental health, and physical care (cite). Maternity Group Homes for pregnant and parenting youth teaches parenting skills, health and nutrition (cite). Street Outreach Program which helps runaways, homeless and street youth find housing and services (Federal Programs, 2010). Although, resources to aide youth affected by homelessness are available, they are scarce, present with barriers and lack an OT approach. Some barriers include funding for occupational therapy practitioners (OTPs), programs or services having inflexible entry criteria, complexity of service systems, homeless youth feeling devalued; and a lack of communication between services (Black et al., 2018).

As of 2021, literature on the role of OTPs working in homeless youth shelters is limited. Research primarily focuses on the medical needs of youth affected by homelessness (YEH). Therefore, research on needs such as mental health and life skills supported by OTPs is limited (Aviles \& Helfrich, 2004). The services available to homeless youth are incongruent to their current needs (Christiani et al., 2008). YEH lack life skills and may need development in areas such as social participation, health management, meal preparation, financial management, and employment (Thomas, et al., 2010). OTPs are skilled in addressing life skills in the homeless youth population (Helfrich et al., 2006). By examining this population from an OT perspective, 
determining what their needs are in their various occupations, and identifying the barriers they are encountering, may contribute to promoting the well-being of these youth (Black et al., 2018).

There is an increasing need for occupational therapy services for people experiencing homelessness (Roy et al., 2017). Occupational therapy practitioners can blend expertise from various practice areas to meet the diverse needs of this population (Schultz-Krohn, 2018). The United States Interagency Council has identified six areas that are consistently identified as necessary to address and prevent youth homelessness. These include individualized goal-based service planning, ongoing support services connected to mainstream resources, independent living skills training, connection to supportive and trustworthy adults, employment and education, and housing. All of which are areas OTs are trained to enhance.

The person environment and occupation (PEO) model and the framework of occupational justice (FOJ) are the best to support this project. The PEO is a model that emphasizes occupational performance shaped by the interaction between person, environment, and occupation. The person domain includes role, self-concept, cultural background, personality, health, cognition, physical performance, and sensory capabilities (Law,1996). The FOJ offers an occupational perspective of justice or injustice on everyday occupations, by illustrating how the inter-relationships of structural factors and contextual factors support or restrict occupational outcomes and occupational rights (Townsend, 2012). By understanding the PEO and FOJ, this study will be able to analyze the occupational performance and dysfunctions of youth living in a shelter.

\section{Statement of the Problem}

The problem is there is a lack of OT services in homeless youth shelters to address occupational performance in youth who are at risk for occupational deprivation. Five basic 
categories of children's needs were identified: the need for stimulation, the need for a meaningful world, the need for love and emotional security, the need for identity and finding one's place in society, and the need for life perspective and open future (Glumbíková et al., 2020). Homeless youth living in homeless shelters do not receive sufficient occupational therapy interventions/services focusing on needs such as life skills and mental health training (Aviles et al., 2004), to successfully transition into the community. There is also limited research on the role of OTPs in youth shelters. By exploring the potential benefits of OT roles in youth shelters can provide the necessary justification for establishing OT services in homeless youth shelters and lead to the development of life skills programs guided by OTPs. This capstone project will contribute to increased knowledge regarding the role of occupational therapists in youth shelters.

\section{Purpose Statement}

The purpose of this qualitative research project is to explore the occupational performance and occupational deprivation experienced by youth in homeless shelters. A better understanding of the activities that are available, as compared to restricted activities will improve the understanding of the occupational dysfunction of the population. A better understanding of the occupational dysfunction will provide for the opportunity of occupational therapists and other stakeholders serving the population to provide services assisting the youth and occupational therapist in establishing goals and plans of care to address the occupational dysfunction. The population experience improved occupational performance, and improved quality of life. The following research questions will be answered: What are the most frequent occupational performance problems for youth in homeless shelters? What is the most frequent occupational dysfunction for youth in a homeless shelter? The Canadian occupational performance measure 
(COPM) and modified occupational dysfunction survey (MODS) will answer the research questions.

It is hypothesized that, the most frequent occupational performance measures would consist of low perception on performance of meaningful tasks, and that the most frequent occupational dysfunction for youth in a homeless shelter would be occupational deprivation. Youth in shelters can benefit from OT interventions because occupational therapy practitioners can blend expertise from various practice areas to meet the diverse needs of this population (Schultz-Krohn et al., 2018). The five main life skills identified by the WHO, will be used for clinical reasoning and referenced for this research project.

\section{Rationale for Proposed Project}

The rational for this research type capstone project is to contribute to the homeless youth population, and the OT profession, by exploring the role of occupational therapy in a setting deprived of OT services, where OT intervention could be of great value. This project will enhance the activities of daily living, improve lives of the youth they serve, provide as a source of advocacy for the occupational therapy profession, and provide as a guide to prevent future adult homelessness. There are a variety of factors affecting youth that are homeless, and their development of life skills to support independent living. These factors include mental health obstacles, educational obstacles, job attainment obstacles, and money management difficulty.

This project is important because it will identify the role of occupational therapy in homeless youth shelters. Once the role is identified, due to the research conducted, a program developing life skills in homeless youth led by an occupational therapist using occupation-based interventions can begin development and later be implemented. Other stakeholders can benefit from this research by offering education on the importance and roles of occupational therapy. With 
a clear role and understanding of how OT can be implemented and what OT is, shelter coordinators and supervisors would better be able to serve homeless youth.

\section{Significance for Proposed Project}

The significance of this qualitative research type project is to fill the gap between occupational therapy and homeless youth shelters. Little has been published about the role of occupational therapy working with the homeless (Lloyd \& Bassett, 2012). A better understanding of the occupational dysfunction will provide for the opportunity of occupational therapists and other stakeholders serving the population to provide services assisting the youth and occupational therapist in establishing goals and plans of care to address the occupational dysfunction. In return providing the population with improved occupational performance, and improved quality of life.

This project has the potential to open doors and explore the possible implementation of OT services in a setting with little to no exposure of occupational therapy interventions. This project can expand on the awareness and knowledge of OT leading to future collaborations between professions to aide in the positive development of a population. This project can benefit youth affected by homelessness, by leading to the development of a program that will provide services and an equitable opportunity for homeless youth to develop skills necessary to transition and participate in society.

\section{Connection to Theory}

The occupational therapy theory approach would be the person environment occupation model (PEO), and the framework of occupational justice (FOJ). The PEO model focuses on the occupational performance shaped by the interaction between person, environment, and occupation. These elements are dynamic and they continue throughout the lifespan (Law., et al 
1996). The person domain includes role, self-concept, cultural background, personality, health, cognition, physical performance, and sensory capabilities. The environmental domain includes physical, cultural, institutional, social, and socio-economic environment. The occupation refers to the groups of tasks that a person engages in and meets his/her self-maintenance, expression, and fulfillment. The three domains are dependent and affected by each other (Law et al., 1996). Depending on the environment of the shelter an occupational therapist can make adjustments, see how the adjustments affect those serviced, and make changes to improve occupational performance. OT holistic interventions along the lifespan of the affected people can facilitate activities of daily living and can support the homeless population by addressing each person's strengths and challenges (Van Oss et al., 2018).

The FOJ offers an occupational perspective of justice or injustice on everyday occupations, by illustrating how the inter-relationships of structural factors and contextual factors support or restrict occupational outcomes and occupational rights (Townsend, 2012). The FOJ is the access to and participation in the full range of meaningful and enriching occupations afforded to others, including opportunities for social inclusion and the resources to participate in occupations to satisfy personal, health, and societal needs (Townsend et al., 2004).

\section{Objectives:}

This section consists of the learning and project objectives for this qualitative research.

\section{Learning objectives:}

- Document specifically, from evidence the scope of practice for OT's in youth shelters.

○ Deliverable - This objective will be measured by a document identifying how OT's can serve in youth shelter 
- Document and learn about how OT's can be funded in youth shelters Policy/knowledge.

Deliverable - This objective will be measured by a document of how OT's can be funded, identify any policy that supports payment for services to homeless youth.

- Analyze current programs and activities available at a youth shelter, for current life skills being taught.

○ Deliverable - This objective will be measured by a document containing information of what is currently being offered to youth in a shelter

- Based on research develop a survey to understand the needs of YEH.

- Deliverable - This objective will be met with the development of a Survey that can be used to analyze the needs of YEH

- Use COPM to identify the occupational performance measures of youth in a shelter.

○ Deliverables: This objective will be met with a document identifying the occupational performance results of youth in a shelter.

\section{Project objectives:}

1. Identify the role of occupational therapist in youth shelters, by providing fundamental objectives for occupational therapist working in youth shelters.

○ Deliverable - This objective will be met with a completed qualitative research valuable to both stakeholders and those interested in the homeless youth population.

2. Allow open dialog between OT's and homeless youth shelter coordinators, for implementation of OT services. 
○ Deliverable - This objective will be met by serving as an advocate for OT services in a youth shelter with results documented

3. Identify what skills would benefit YEH so they can live independently.

○ Deliverable - This objective will be met by document identifying the most needed skills in a youth shelter

4. Analyze scores of COPM assessment to record occupational performance.

- Deliverable - This objective will be met with a document with the occupational performance measures of homeless youth.

5. Analyze results of modified occupational dysfunction survey.

○ Deliverable - This objective will be met with a document identifying the most common occupational dysfunctions of homeless youth.

6. Provide a research study to be used as an outline for future program development incorporating life skills via OT intervention.

○ Deliverable - This objective will be met with a document that provides an outline for a life skills program that would benefit all stakeholders and those interested in the homeless youth population.

- Write chapters $4 \& 5$ of the capstone paper.

- Deliverable - All chapters of the capstone paper are completed.

- Submit completed and approved project (Chapter 1-5 plus appendices) into SOAR. 


\section{Definition of terms}

- Life Skills: “Those abilities that help to deal with challenges in life and to promote physical, mental, and emotional well-being and competence” (Abaoğlu et al., 2017, para. 4 ).

- Mental Health: "Mental health is a state of well-being in which an individual realizes his or her own abilities, can cope with the normal stresses of life, can work productively and is able to make a contribution to his or her community" (Who.gov, 2018, para. 2).

- Occupational Deprivation: "Prolonged restriction from participation in necessary or meaningful activities due to circumstances outside the individual's control. Geographic isolation, incarceration, disability, or social exclusion may contribute to such circumstances" (Medical Dictionary, 2009, para. 1).

- Occupational Dysfunction: "Is defined as a negative experience related to engaging in daily activities, and has four components; occupational marginalization, occupational imbalance, occupational alienation, and occupational deprivation. (Teraoka et al., 2015, p. 1).

- Couchsurfing: "Stay temporarily in a series of other people's homes, typically making use of improvised sleeping arrangements" (Oxford Dictionary, 1992).

\section{Assumptions}

Assumptions of this capstone project include that occupational therapist, shelter coordinators, and supervisors are unaware of the positive impact OT's can have on the development of youth in shelters across the life span. It is assumed that youth in shelters would benefit from OT intervention to transition into the community. It is also assumed that the coordinators, and supervisors in the youth shelter will be open to the idea of analyzing current 
programs and will present with honesty and truthfulness while completing the COPM and MODS. It is assumed that all parties involved have an interest in supporting this project with no other motive for supporting the researcher.

\section{Limitations}

Limitations of this capstone project include a difference in needs across shelters, financial and staffing resources, time restraints, and unforeseen circumstances such as COVID-19, and the willingness of individuals to complete interviews and surveys. Each youth shelter has their own demographics with a difference in age, race, and sex, meaning what may work at one particular shelter may not necessarily work in another. Another limitation to consider is the financial and staffing resources of the site. Site supervisors and coordinators could become overwhelmed with the amount of work that they must do and may not have time to participate in the research appropriately. External factors such as time restraints as to when the researcher can observe at the shelter, as well as pandemics such as COVID-19 can prohibit research from taking place and may call for changes in how the research is completed.

\section{Delimitations}

A qualitative form of research was chosen due to the plausible sample size of participants. The project invites shelter staff, coordinators, and supervisors, and attendees to participate in open ended questions, to identify areas in which an occupational therapist would be of benefit. Data will be collected via COPM and MODS allowing for both open ended and closed ended answers. The youth that participate in the COPM and MODS will do so anonymously. 


\section{CHAPTER II: Literature Review}

\section{Introduction}

The role of an OT working in homeless youth shelters has yet to be defined. The purpose of this qualitative research capstone project is to explore the role of OTs in a youth shelter by identifying the barriers to OT intervention, measuring the occupational performance, and occupational dysfunctions of youth living in a youth shelter. The problem is there are few research studies that identify the role of occupational therapist working with the homeless (Lloyd et al., 2012). Research primarily focuses on the medical needs of YEH. Therefore, research on life skill needs supported by OTPs is limited (Aviles \& Helfrich, 2004). There are eight occupations which OTs are trained to address: activities of daily living, instrumental activities of daily living, sleep and rest, work, education, play, leisure, and social participation (AOTA, 2021). Youth need to acquire basic life skills to successfully transit out of homelessness (Aviles et al., 2004; Koegel et al., 1995; Reid et al., 1999). In addition to these services, youth reported a need for assistance in planning, advice, support, encouragement, and life skill training from service providers (DeRosa et al., 1999). The homeless youth population is at a high risk for factors such as unemployment, low educational attainment, early parenthood, criminal activity, and mental health conditions (Daining \& DePanfilis, 2007).

The purpose of this literature review is to provide an overview of literature that already exist exploring how OTs can work with youth in a shelter and measure the occupational performance deficits and occupational dysfunctions of youth living in a shelter. Common variables across literature presented with a lack of OT representation in homeless youth shelters, a lack of research on OT roles in homeless youth shelters, and the possible benefits of OT 
intervention on youths affected by homelessness. There is substantial evidence based on literature on the positive impact of OT interventions on the development and advancement of youth affected by homelessness. Yet, many programs lack OT representation due to barriers explored in the literature. The review was conducted using several databases, such as Pubmed, Proquest, and the University of St Augustine for Health Sciences database. Literature from third party sources was also explored as literature is limited. The following key terms were used to search for literature: homeless youth, occupational therapy, life skills, occupational performance, and occupational dysfunction.

This chapter will further explore the common themes presented in the literature and research as it will be used to explore and define OTs role in a homeless youth shelter, the benefits of OT intervention on YEH, analyze the barriers limiting OT intervention in youth shelters, and the theory supporting the research. The following themes will be explored:

1. Youths Affected by Homelessness

2. Challenges and Health Disparities for Youth Affected by Homelessness

3. Current Gap in Services

4. OT Role Serving Youth Affected by Homelessness

5. Theoretical Support for the Research project

6. Conclusion

\section{Youth Affected by Homelessness}

Homeless youth are those aged under 25 who lack a stable living situation in the present and near future, including individuals who live in a place not meant for human habitation, such as the streets or in their car, emergency shelter, transitional housing, or hotel paid for by a government or charitable organization (Federal Definitions, 2011). In the United States there are 
currently 4.2 million youth between the ages of 13 and 25 that have been considered homeless (McCann, 2019). Literature identifies various reasons for youth homelessness. Different individual, psychological and environmental factors, such as abuse, mental illness, and substance use, combine or interact to result in youth homelessness (Jeanis et al., 2018). The National Conference of State Legislators, states that members of the LGBTQ+ community have more than twice the risk of becoming homeless, and females are more likely to run away than males.

The cause of homelessness has been conceptualized as a complex integration of structural and individual factors that result in different pathways into a homeless lifestyle (Minnery et al., 2007). The homeless population is at high risk for unemployment, low educational attainment, early parenthood, criminal activity, and mental health conditions (Daining et al., 2007). Twentynine percent of homeless youth report having substance abuse problems, $69 \%$ have reported mental health problems, while $50 \%$ of adolescents aging out of foster care and juvenile justice systems will be homeless within 6 months because they are unprepared to live independently (Teen Homelessness Statistics, 2021).

Although, many of the youths affected by homelessness have family, some are escaping some form of abuse from their family, or their family too is homeless. Some homeless youth may sleep on the streets, in their car, "couch-surf" and / or seek services from a shelter. The amount of time a youth can stay at a shelter is dependent of the rules of that individual shelter. According to a study completed by "streetworks" a community outreach program, some shelters can only provide a 3-5 day stay, while others 30 days, some 90 days, and some even provide long term housing.

\section{Challenges and Health Disparities for Youth affected by Homelessness}

There are many challenges homeless youth are more subjectable to such as unstable 
housing, financial illiteracy, and trauma from physical and sexual abuse. Two common variables among literature are the development of necessary life skills, and concern for mental health needs to be met. Factors preventing the development of these life skills vary among youth. For example, those experiencing long-term homelessness need services to meet their basic needs, such as food, clothing, financial assistance, education, care and comfort along with basic daily life skills and a desire to develop skills that would help them to contribute to society (Grandisson et al., 2009).

Life skills are necessary for individuals to live equitably in the community. Life skills development includes skills such as social participation, health management, meal preparation, financial management, employment, and interpersonal communication. The literature informs readers of the disadvantages homeless youth are posed with and the positive impact a life skills program can have on their development. Children and adolescents need lifelong skills to build better futures for themselves, their families, and their communities (UNICEF, 2019). Life skills also help children and adolescents to improve their psychosocial competence which is important to deal with challenges of daily life, promotion of health, and well-being. Therefore, the teaching of life skills to children and adolescents is one of the core elements to develop psychosocial competence (Abaoğlu et al., 2017; Weisen et al., 1994). Between the ages of 10-13 a child should learn how to change their own bed sheets, use a washing machine and dryer, plan and prepare a meal with several ingredients, read labels, iron clothes, and use basic tools. While youth between the ages of 14 to 18 should be able to perform more sophisticated cleaning and maintenance chores, fill a car with gas, read and understand medicine labels, and interview for and get a job (Hutton, 2018). 
In addition to the development of life skills, research indicates that mental health and environment affect occupational performance. Youths who are homeless desire mental health services and are especially enthusiastic about programs that address interpersonal difficulties and emotion regulation report high rates of trauma and subsequent mental health problems among homeless youths (Winiarski, 2021). For example, in a large study of homeless youth from several major cities in the United States, $57 \%$ of the 146-sampled youth experienced a traumatic event and 24\% met Diagnostic and Statistical Manual of Mental Disorders-IV criteria for posttraumatic stress disorder (Bender et al., 2010). Other literature stresses the numerous amount of mental health issues YEH may face and the fact that the lifetime prevalence of mental health disorders in homeless youth is almost double that of youth who are not homeless (Whyte, 2019). Mental health concerns common in the homeless youth population include conduct disorder, ADHD, mood disorders, mania or hypomania, PTSD, and schizophrenia. Compared to nonhomeless youth these mental disorders are more prevalent and in some cases are 10 times more likely (Hodgson et al., 2013). According to the Centers for disease Control (CDC, 2021), and the National Alliance on Mental Illness (NAMI, 2021) the following are the percentages for different mental health disorders in the homeless youth population compared to the national youth population: conduct disorder: $53 \%$ National: $7.4 \%$, any substance use disorder: $28 \%-81 \%$ (estimates vary) National: 4.0\%, ADHD: 32\% National: 9.4\%, depression: $21 \%$ National: $6.1 \%$, anxiety: $22 \%$ National: $10.5 \%$, mania or hypomania: $21 \%$ National: $3.1 \%$, PTSD: $12 \%$ National: 5.3\%, schizophrenia: $10 \%$ National: $0.23 \%$.

Both life skills development and mental health concerns are prevalent in the YEH population according to the literature. Occupational therapy is the only profession that helps people across the lifespan to do the things they want and need to do through the therapeutic use 
of daily activities (occupations). Occupational therapy practitioners enable people of all ages to live life to its fullest by helping them promote health, and prevent or live better with injury, illness, or disability (AOTA, 2021), making the perfect profession to enable youth affected by homelessness.

\section{Current Services for Youth Effected by Homelessness}

According to Adrienne L. Fernandes-Alcantara, a specialist in social policy, on a report on runaway and homeless youth demographics and programs, there are federal services that come to the aid of homeless youth by providing shelter, clothing, and meals. These programs include the Basic Center Program (BCP), Transitional Living Program (TLP), and Street Outreach Program (SOP). The BCP provides shelter up to 21 days, counseling, and after care services to runaway and homeless youth under age 18 and their families. The Transitional Living Program is targeted to older youth ages 16 through 22 . Youth who use the TLP receive longerterm housing with supportive (Fernandes-Alcantara, 2019). The SOP provides education, treatment, counseling, and referrals for runaway, homeless, and street youth who have been subjected to or are at risk of being subjected to sexual abuse, sex exploitation, and trafficking (Fernandes-Alcantara, 2018).

Funding for Runaway and Homeless Youth Program is administered by the Family and Youth Services Bureau (FYSB) within the U.S Department of Health \& Human services (HHS) Administration for Children and Families (ACF) (Fernandes-Alcantara, 2018). In 2018 the State of Florida BCP received $\$ 2,983,193$, where the grants were allocated directly to non-profit applicants (Fernandes-Alcantara, 2018). Qualifying applicants received a minimum allotment of $\$ 200,000$. The costs of the BCP are shared by the federal government (90\%) and grantees (10\%) (Fernandes-Alcantara, 2018). TLP grants totaled \$19.2 million as TLP includes maternity group 
homes, and special populations such as LGBTQ youths (Fernandes-Alcantara, 2018). SOP are granted a minimum of $\$ 100,000$ a year and a maximum of $\$ 200,000$. In 2016, 103 grantees were funded, and 36,126 youth were contacted (Fernandes-Alcantara, 2018). Additional funding is acquired from the U.S department of Housing and Urban Development (HUD). In 2018 HUD granted \$80 million dollars to implement projects that demonstrate how a "comprehensive approach" can "dramatically reduce" homelessness for youth through age 24 (FernandesAlcantara, 2018).

As to how effective these programs are, the literature varies. In 2008, multiple federal agencies came together in a strategy to end youth homelessness by 2020 (Fernandes-Alcantara, 2018). This research project is taking place in 2021 and youth homelessness is still of great concern. In a study analyzing if programs for runaway and homeless youth work, it was found that the youth in BCP and TLP programs found them to be lifesaving, and life changing by providing service needs (Gwadz et al., 2018). While, according to Winiarski, an estimated 50\% of transition-age homeless youth continue experiencing housing instability and/or homelessness into adulthood. Based on literature, the effectiveness of a program is independent on resources available in the program, and the individual factors of the YEH.

\section{Current Gap in Services}

Although there are services available for $\mathrm{YEH}$, the services available to homeless youth are incongruent to their current needs (Christiani et al., 2008), contributing to an increased chance of homelessness into adulthood. Most shelters have a limit on the amount of youth they can accommodate presenting with a barrier. The research indicates that there is an array of barriers preventing YEH from seeking services. Some barriers include lack of knowledge of available resources, inflexible entry criteria for programs or services, complexity of service 
systems, devaluation of homeless youth, and a lack of communication between services (Black et al., 2018). There is a lack of knowledge of resources that are available to youths in youth shelters. In a study conducted by Heinze and Jozefowicz-Simbeni (2009) staff reported more than twice the number of services and resources provided to youth than youth reported were provided to them, which suggests that youth may not be aware of all services available to them.

Other literature reports that services are not always easy for this population to access. Some of the barriers to access include age, fear of parents or social services being contacted, lack of transportation, lack of insurance, lack of social support, fear of judgment, and lack of knowledge about existing programs (Slesnick et al., 2008), which serves as a deterrent for youths seeking services. Nonetheless, many of these shelters lack the representation of occupational therapists. Shelter workers are typically unaware of the profession of occupational therapy and the important role that those practicing the profession could play in enabling autonomy in the areas of self-care, productivity, and leisure (Finlayson et al., 2002).

In addition to a lack of awareness of what OT is, according to the literature OTPS do not feel prepared when working in this setting. The reason for the uncertainty in regard to the homeless population is due to feeling unprepared regarding specific theories and skills of community development and strategies for working at the broader systemic levels of the community (Lauckner et al., 2007). An emphasis on the need for education on the topic of homelessness in the undergraduate curriculum and the need for continuing education for those clinicians who are already in the field (Lauckner et al., 2007). The literature also indicates that there is a lack of funding for occupational therapists to provide services in the setting as financial support for occupational therapy positions in community development was perceived as limited because there was not a widely recognized role for occupational therapists in this field (Lauckner 
et al., 2007). The literature states people do not know what OT is, so there is a need for advocacy and education (Davis-Worden,2017).

\section{OT Role serving Youth Affected by Homelessness}

The literature presents that there is an increasing need for occupational therapy services for people experiencing homelessness (Roy et al., 2017). Occupational therapy practitioners can blend expertise from various practice areas to meet the diverse needs of this population (SchultzKrohn, 2018). The United States Interagency Council has identified six areas that are consistently identified as necessary to address and prevent youth homelessness. These include individualized goal-based service planning, ongoing support services connected to mainstream resources, independent living skills training, connection to supportive and trustworthy adults, employment and education, and housing. All of which are areas OTs are trained to enhance.

Due to the OT holistic approach occupational therapists can assess situations and implement interventions to develop life skills in homeless youth. An example of this is a program that was implemented by the AOTA. Project Employ is a grant-funded 14-week program that provides occupational therapy services to those who are homeless (Muñoz, et al., 2006). Within Project Employ, occupational therapists run a Life Skills program that addresses time and stress management, conflict resolution, health and wellness, and goal setting. Therapists complete the Canadian Occupational Performance Measure (COPM) (Law et al., 2014) to help the participants develop a plan to address their self-identified goals (Van et al., 2018).

Chapleau et al. (2012) investigated the effect of the occupational therapy consultation model on 57 homeless individuals at a drop-in shelter. Researchers found that when occupational therapy group services were provided to homeless individuals, clients achieved their goals in several areas including money management, community mobility, addiction, personal hygiene, 
social skills, and diabetes management. (Van Oss., et al., 2018). OTs can also be involved in many ways when it comes to homeless youth; they can advocate and take part in an annual Point in Time Count (National Alliance to End Homelessness [NAEH], 2020). This event is a count of sheltered and unsheltered homeless persons in a specific location on a given night in January (NAEH, 2020). This information helps to establish the dimensions of the problem of homelessness in a community to help policymakers and program administrators track progress toward the goal of ending homelessness (NAEH, 2012; Van et al.,2018). Occupational therapists can volunteer or work in a homeless shelter, become immersed in the environment and population, gain understanding, observe and develop assessments and interventions to help serve that population. Whether it may be social participation, health management, meal preparation, financial management and employment, the holistic approach allows occupational therapists to help develop these necessary life skills in homeless youth. The role of occupational therapy is to establish or re-establish occupations (Schultz-Krohn., et al, 2018).

\section{Theoretical Support for the Research Project}

Based on the literature, the model best used for this research is the PEO model and the best framework is occupational justice (FOJ). The PEO Model is built on the theory that interaction of the person, environment, and occupation facilitates participation (Wong et al., 2018).The person domain includes role, self-concept, cultural background, personality, health, cognition, physical performance, and sensory capabilities (Law,1996). The environmental domain includes physical, cultural, institutional, social, and socio-economic environment. The occupation refers to the groups of tasks that a person engages in and meets his/her selfmaintenance, expression and fulfillment. This particular model helps therapists to conceptualize, plan, communicate and evaluate occupational performance interventions (Strong et al., 1999). 
The three domains are dependent and affected by each other (Law, 1996). Depending on the environment of the shelter an occupational therapist can make adjustments, see how it affects those it services and make changes to improve occupational performance. OTs can use the COPM to measure the occupational performance of homeless youth. Occupational therapy's holistic interventions along the lifespan of the affected people can facilitate activities of daily living and can support the homeless population by addressing each person's strengths and challenges (Van Oss et al., 2018).

The FOJ offers an occupational perspective of justice or injustice on everyday occupations, by illustrating how the inter-relationships of structural factors and contextual factors support or restrict occupational outcomes and occupational rights (Townsend, 2012). FOJ is the access to and participation in the full range of meaningful and enriching occupations afforded to others, including opportunities for social inclusion and the resources to participate in occupations to satisfy personal, health, and societal needs (Townsend et al., 2004). This framework aims to develop a just society with inclusion of all citizens in everyday occupations (Townsend et al., 2004). Occupational injustices on everyday occupations then leads to occupational dysfunctions. Occupational dysfunctions include occupational marginalization, occupational imbalance, occupational alienation, and occupational deprivation (Teraoka, et al., 2015).

\section{Conclusion}

There are few research studies that identify the role of occupational therapists working with the homeless (Lloyd, et al, 2012). Research findings have indicated that individuals experiencing homelessness are provided with limited opportunities to engage in meaningful occupations and therefore have decreased health outcomes, social interactions, and well-being (Glass et al., 2006). The literature shows that OT representation is beneficial to the development 
of life skills, and mental health of youth affected by homelessness to have an equitable chance to become successful and functioning members of society. However, there are many barriers affecting the relationship between occupational therapist, shelters and those they serve.

Traumatic, experiences can have a negative impact on one's mental health leaving homeless youth open to many mental disorders, while a lack of resources can delay and/or inhibit the development of essential life skills. Through OT assessments like the COPM observation and surveying the implementation and role of OT in homeless youth shelters will be defined through this research project. 


\section{Chapter III: Project Description}

\section{Introduction}

The problem is there is a lack of OT services in homeless youth shelters to address occupational performance in youth who are at risk for occupational deprivation. The purpose of this capstone project was to explore the occupational performance and frequent occupational dysfunction experienced by youth in homeless shelters. In this project the role of occupational therapists in homeless youth shelters will be explored and identified. Given the evidence presented in the literature review, more research is to be conducted through observation, assessment, and survey to analyze the need for OT services and identify therapist roles in homeless youth shelters. The project assessed the gap between occupational therapists and youth shelters by revealing barriers, while simultaneously developing a role for occupational therapists in homeless youth shelters. Data was collected from a homeless youth in a shelter in the southeast region of the United States. The data was analyzed to identify the role of occupational therapists working with the homeless youth shelter population.

\section{Objectives}

The proposed project was supported by the following objectives:

\section{Learning objectives:}

1. Document specifically, from evidence the scope of practice for OT's in youth shelters.

○ Deliverable - This objective will be measured by a document identifying how OT's can serve in youth shelter

2. Document and learn about how OT's can be funded in youth shelters Policy/knowledge. 
○ Deliverable - This objective will be measured by a document of how OT's can be funded, identify any policy that supports payment for services to homeless youth.

3. Analyze current programs and activities available at a youth shelter, for current life skills being taught.

○ Deliverable - This objective will be measured by a document containing information of what is currently being offered to youth in a shelter

4. Based on research develop a survey to understand the needs of YEH.

- Deliverable - This objective will be met with the development of a Survey that can be used to analyze the needs of $\mathrm{YEH}$

5. Use COPM to identify the occupational performance measures of youth in a shelter.

○ Deliverables: This objective will be met with a document identifying the occupational performance results of youth in a shelter.

\section{Project objectives:}

1. Identify the role of occupational therapist in youth shelters, by providing fundamental objectives for occupational therapist working in youth shelters.

- Deliverable - This objective will be met with a completed qualitative research valuable to both stakeholders and those interested in the homeless youth population.

2. Allow open dialog between OT's and homeless youth shelter coordinators, for implementation of OT services.

○ Deliverable - This objective will be met by serving as an advocate for OT services in a youth shelter with results documented

3. Identify what skills would benefit YEH so they can live independently. 
○ Deliverable - This objective will be met by document identifying the most needed skills in a youth shelter

4. Analyze scores of COPM assessment to record occupational performance.

o Deliverable - This objective will be met with a document with the occupational performance measures of homeless youth.

5. Analyze results of modified occupational dysfunction survey.

○ Deliverable - This objective will be met with a document identifying the most common occupational dysfunctions of homeless youth.

6. Provide a research study to be used as an outline for future program development incorporating life skills via OT intervention.

○ Deliverable - This objective will be met with a document that provides an outline for a life skills program that would benefit all stakeholders and those interested in the homeless youth population.

7. Write chapters $4 \& 5$ of the capstone paper.

○ Deliverable - All chapters of the capstone paper are completed.

8. Submit completed and approved project (Chapter 1-5 plus appendices) into SOAR.

\section{Process \& Methods:}

\section{Research Questions and Hypothesis}

1.) What are the most frequent occupational performance problems for youth in homeless shelters?

2.) What is the most frequent occupational dysfunction for youth in a homeless shelter?

It was hypothesized that the most frequent occupational performance measures would consist of low perception on performance of meaningful task, and the most frequent occupational 
dysfunction for youth in a homeless shelter would be occupational deprivation based on literature.

\section{Research Design}

The research design required 14 weeks to be completed, starting with building rapport with staff, coordinators, supervisors, and youth at a shelter. Rapport was built by participating in staff meetings, participating in programs available, and conversing with youth and staff. Once rapport was established, defining the role of OT in youth shelters was identified by COPM assessment, and completion of the MODS by shelter youths. The results from the COPM and data collected from the MODS were analyzed for common themes. Through assimilation, observation, and conversation the barriers to OT intervention were identified.

This project explored how occupational therapists and their training can be integrated and beneficial in homeless youth shelters, to aide in the development of the youths in which they serve and support their transition into the community, by exploring the role of OT in a setting deprived of OT services to enhance activities of daily living and improve lives. There are a variety of factors affecting youths that are homeless such as their development of life skills and their mental health. This makes an OT approach ideal.

Little has been published about the role of occupational therapy working with the homeless (Lloyd \& Bassett, 2010; Murtaghet al., 2010). This project has the potential to advance OTs role and explore the possible implementation of OT services in a setting with little to no exposure of occupational therapy interventions. This project can expand on the awareness and knowledge of OT leading to future collaborations between professions to aide in the positive development of a population. This project can benefit youth affected by homelessness, by 
leading to the development of a program that will provide services and an equitable opportunity for homeless youth to develop skills necessary to transition and participate in society.

\section{Sample: Participants and Recruitment}

The student investigator had no prior affiliation with the shelter or those involved in this study. Participants were recruited from a homeless youth shelter in the southeast region of the United States. Participation in the completement of this research was voluntarily and participants could withdraw at any time. The inclusion criteria includes, youth aged 13-21 living in a youth shelter. Youths under the age of 13 will be excluded from this study. Shelter staff members, coordinators, and youth from the shelter contributed to this research. Permission from shelter supervisor allowing youth to take an assessment and survey will be granted by the signing of the informed consent form.

Participation will consist of youth living in a youth shelter, staff, coordinators and supervisors. It is to be assumed that all individuals who participate in an interviews will be honest with there answers. Youth participants will complete a two-part assessment called the COPM, which will measure the youth's occupational performance. Youths will then volunteer to complete the MODS, which will identify the occupational dysfunctions of the youth. Based on observations, assessments, and surveys, the results will be analyzed to identify the role of OT in homeless youth shelters.

\section{Informed Consent}

Please find informed consent in Appendix B

\section{Instrumentation}

To complete the study, the instrumentation to be used will be to calculate scores from the COPM and data collected from Survey Monkey on the completion of the MODS. Survey 
Monkey is a software program used to analyze qualitative research. The data collected from the assessment, and survey will be entered into the program and themes were generated.

\section{Data Collection and Storage}

The student investigator will collect data from observation, the COPM and the MODS. The COPM is a commonly used interview styled performance measure in the occupational therapy profession. The COPM asked questions about daily activities in self-care, productivity and leisure. The COPM is reliable because it is a standardized assessment based on a set of standard questions asked by the student investigator. The COPM consisted of two sessions, each lasting 20-40 minutes depending on individual responses; and were used to identify everyday issues that restrict their participation in everyday living. The answers were answered by the client based off their own self-assessment. Based on the self-assessment style of the COPM the need for OT services will be identified and validated.

Data will also be collected from the MODS, and then analyzed using survey monkey. The MODS is a survey modeled off the Classification and Assessment of Occupational Dysfunction (CAOD) scale and contains elements of the Casey Life Skills Assessment (CLSA).

The MODS average completion time will be 15-30 minutes and was used to identify restriction from participation in necessary or meaningful activities.

\section{Data analysis}

The student investigator input the data collected from the COPM and MODS into Survey Monkey. The data collected from the literature, learning objectives, interviews, and surveys, were used to measure occupational performance, and the most common occupational dysfunction among youth. This information was used to identify the role of occupational therapists in homeless youth shelters. 


\section{Status of IRB}

The student investigator went through a full IRB review as the population being studied is considered a protected population. An IRB application form was completed and approved by the IRB committee. The application contained detailed information of the recruitment process for youths involved in the study, the student investigator, and the principal researchers. For a more detailed description of the approved IRB form, please see Appendix C.

\section{Alignment with Objectives}

Project objectives will be met based on the research design, timeline, methods, and process. This capstone project aligns with objectives as each objective contributes to the role of OT being identified in homeless youth shelters. Objectives $2-5$ will begin at from the beginning of the study until the completement of all assessments and surveys near the end of the study. Project objectives 1 and 6 will be completed by the conclusion of this study. During the 14-week period of this qualitative study the youths in the shelter will have completed the COPM and MODS, which will be analyzed using survey monkey. The completion of the project objectives will be drawn from common themes identified in the study.

\section{Conceptual Framework}

For conceptual framework please see Appendix D

\section{Timeline}

The qualitative research project was completed within 14 weeks (see Table 1).

\section{$\underline{\text { Table } 1}$}

\section{Timeline}

Weeks Tasks


Weeks - Meet with shelter supervisor to present learning and project objectives

1 - 4 - Partake in daily activities of the shelter and learn daily functionality.

- Participate current programs, offered at the shelter.

- Learn about barriers of OT service implementation in the shelter.

- Inquire from staff their knowledge of occupational therapy

- Learn and inquire about funding and policy at the shelter.

- Discuss with shelter supervisor about potential participants to volunteer for the COPM assessment.

- Begin to identify potential participants for the MODS

Weeks

5- 11 Obtain permission from shelter supervisor to complete COPM assessment with potential volunteers.

- Complete first session of COPM assessment with volunteers.

- Obtain permission from shelter supervisor to complete MODS with potential volunteers.

- Partake in dialog with shelter counselors regarding life skill needs of the youth in the shelter

- Begin to analyze data from completed survey.

- Complete second session of COPM with assessment participants.

Weeks

$12-13$

- Analyze data from COPM and MODS.

- Discussion with OT/site mentor regarding any new concerns

- Document common themes based on data 
Week

- Draw conclusions based on data.

- Discuss with mentors the findings and analysis of the data

Note. Fourteen-week timeline.

\section{Conclusion}

Exploring the role of occupational therapists in homeless youth shelters is important and crucial to the development of life skills and mental health of the youth shelters serve. The homeless populace is at a high risk for factors such as unemployment, low educational attainment, early parenthood, criminal activity, and mental health conditions (Daining \& DePanfilis, 2007). OT practitioners can blend expertise from various practice areas to meet the diverse needs of this population (Schultz-Krohn, 2018). There is an increasing need for OT services for people experiencing homelessness (Roy et al., 2017), but there are some barriers preventing OT services such as funding and a lack of knowledge of what OT is. By interviewing shelter staff workers, occupational therapists, former homeless youth, and surveying youth at the shelter, the barriers to OT intervention will further be explored. Once the barriers and the benefit of OT intervention are identified the role of occupational therapy in homeless youth shelters will be defined. 


\section{Chapter IV: Results and Analysis}

\section{Introduction}

The purpose of this chapter is to provide an overview of the results of the capstone project. This chapter will report on the outcomes of the project related to a lack of occupational therapy services in homeless youth shelters to address occupational performance in youth who are at risk for occupational deprivation. The study was conducted at a homeless youth shelter in the southeast region of the United States. This study collected information from data collected from the COPM, modified occupational deprivation survey, observation, and dialog between shelter staff.

The purpose of this qualitative research project was to explore the occupational performance and occupational deprivation experienced by youth in homeless shelters. The following research questions will be answered in this chapter: What are the most frequent occupational performance problems for youth in homeless shelters? What is the most frequent occupational dysfunction for youth in a homeless shelter? This was be accomplished by completing the project objectives from May $3^{\text {rd }}$ to August $2^{\text {nd }} 2021$ resulting in completing 560 experiential hours. First, the role of occupational therapists in youth shelters was identified by providing fundamental objectives based on exploration for occupational therapist working in youth shelters. Then, the most frequent occupational dysfunction of youths living in youth shelters was identified. Next, skills that would benefit youth affected by homelessness so they can live independently were identified. The themes triggered dialogue among staff at the youth shelter for implementation of OT services and provided an outline for future program development incorporating OT intervention in youth shelters. The goal of reporting the outcomes and providing an analysis is to compare the findings as related to the literature review and report 
the outcomes to evidence synthesis of the knowledge of the homeless and at-risk youth population and application of the knowledge.

In this chapter, the project objectives were met through dialog with shelter staff, observations, COPM, and modified occupational deprivation survey completion by shelter youths. The information gathered was then analyzed to compare commonalities to define the role of occupational therapist in youth shelters and the needs of youth in the shelter. The results and analysis detail the occupational deprivations and dysfunction of youths living in youth shelters, to identify the necessary role of OT services in youth shelters, to identify deprivations to aide in the development of skills that will be beneficial throughout one's life span. The following section will explain the project data collection guidelines.

\section{Data Collection}

The project timeframe consisted of 14 weeks from May 2021 to August 2021 of onsite observation at a youth shelter in the southeast region of the United States. The data collected occurred from week four to week 11 as the dynamics of the shelter were constantly changing. During the 14 weeks the student investigator observed the day-to-day activities of the youth in the shelter, and their interactions with each other, staff, and counselors. The shelter provided youth with their basic needs, a daily schedule from 6:30 a.m. to 9:00 p.m., weekly sessions with the shelter counselor, daily group sessions, and weekly reflections. There were staff meetings held once a month, but only for each department head.

Data was collected using the COPM and modified occupational deprivation survey. The COPM consisted of two sessions, each lasting 24 minutes depending on individual responses, and was used to identify everyday issues that restrict their participation in everyday living. The MODS average completion time was 15-30 minutes and was used to identify restrictions from 
participation in necessary or meaningful activities. In addition to the data collected from the assessment and survey general demographics were collected such as the youths age, sex, and length of stay at the shelter.

The participants were recruited through volunteer convenience sampling and permission was granted by the shelter supervisor. Daily the student investigator would obtain permission from the shelter supervisor to interview youth of interest. Volunteers were then approached verbally by the student investigator to participate in the COPM or the modified occupational dysfunction survey (MODS). Nine participants volunteered to participate in the study, five males and four females, all of which were residents of the shelter.

There was one youth who did not want to participate in the study. This youth was a 15year-old male who barely participated in group sessions, recreational activities, and individual sessions with the counselors. Each COPM assessment took 20-40 minutes to complete and consisted of two sessions. While each MODS survey took 15-30 minutes to complete. To ensure that there were no interruptions during the completion of the COPM and MODS survey, sessions were scheduled during each individual youth "free time," usually before lunch around 11:00 a.m. to $12: 30$ p.m.

\section{Project Objectives and Deliverables:}

- Identify the role of occupational therapist in youth shelters, by providing fundamental objectives for occupational therapists working in youth shelters

○ Deliverable - This objective was met with a completed qualitative research study valuable to both stakeholders and those interested in the homeless youth population. 
- Due to observation, the COPM, and occupational dysfunction survey the student investigator found that youth in homeless shelter are deprived of skills, such as emotional, interpersonal, and social skills. In return results in poor communication, social awareness, self-awareness, self-management, and interpersonal relationship skills.

○ A common theme among youth 15-17 in the shelter was the interest in job obtainment to earn money, without any current program educating the youth on how to get a job. Among ages nine to 14 a common theme was the need for proprioceptive touch with a sense of well-being.

- The role of an occupational therapist in a youth shelter will be to first identify the occupational dysfunctions and performance deficits of the youth and then create a program based on the findings that will enable and enhance skills to participate in the community.

- An occupational therapist in a youth shelter shall be able to create a program consisting of life skills, that will enhance each youth's life.

- Allow open dialog between occupational therapists and homeless youth shelter coordinators, for implementation of OT services

- Deliverable - This objective was met by serving as an advocate for OT services in a youth shelter with results documented

O Once a month the head of each department meets to discuss individual youth goals, progress, and daily operations of the shelter. In which there is no OT participation, collaboration, or sessions discussed in the monthly meetings. 
○ Through participation in staff meetings, it was concluded that not everyone knew what occupational therapy was. This allowed the student investigator to educate on the services occupational therapist can provide. It was explained that through assessments and observation, the occupational performance of youth could be measured and the occupational dysfunction of the youth in the shelter could be identified. This information can then be used to develop a life skills program, to enhance the lives of those in the shelter.

- Supervisor: A huge barrier to OT services is the lack of funding available, to afford an occupational therapist. The supervisor mentions that funding for the shelter is provided by the state, grants, and donations from donors. She mentions that the shelter is already understaffed, which she believes is due to the low salary the shelter can offer.

○ Counselor: The counselor did not know how occupational therapists can help the youth in shelter. The counselor identifies occupational therapy as a profession that aids in the rehabilitation of someone who has been injured.

- Staff 1: The staff member mentioned that they are the ones who spend the most amount of time with youth and understand their needs more than the department heads. If they were to mention OT services, due to a lack of knowledge of what OT is and the needs of the youth OT services are not considered to be a priority to the department heads.

○ Staff 2: There is miscommunication between the different departments. Things that are said or agreed upon in the meetings are not always communicated to the staff, as there are no staff meetings. 
- Identify what skills would benefit YEH so they can live independently

○ Deliverable - This objective was met by document identifying the needs of youths in a youth shelter

- The COPM, modified occupational dysfunction survey, and observations were used to identify occupational performance measures, and deprivations. Compared to literature the data is reflective.

- Youth 1: Wants to become a fire fighter when they become of age but is not sure of the requirements. An OT led program will expose youth in the shelter to different careers and provide a general path to each career.

○ Youth 2: Wants to work with youth in a shelter, just like her. She wants to be able to help those that have been through similar situations. An OT led program would expose the youth to different volunteer opportunities, that can create a path for future employment

○ Youth 3: The youth does not care about school, because they believe that they will fail anyway. The youth has not thought about what they want to be when they grow up nor do they understand the importance of thinking about this decision now. This youth does not care to make friends in the shelter, nor to have friends outside of the shelter. Unlike most youth their age, they do not miss their family or using their cellphone to communicate with others. An OT will be able to identify this and help develop the meaningful occupations to the youth.

○ Youth 5: Does not care to make friends in the shelter and misses their friends outside of the shelter. They have expressed that this was their fifth shelter in the last year and that nobody wants him. Their mother passed away and their father is 
in jail. An OT will be able to identify this and help develop the meaningful occupations to the youth, and then help to develop those skills.

- Sessions consisting of resume writing, job research, yoga, arts, and crafts, improving cognitive, emotional, interpersonal, and social skills would be of great benefit for the youth in the shelter.

- Provide an outline for future program development incorporating life skills via OT intervention.

- Deliverable - This objective will be met with a document that provides an outline for a life skills program that would benefit all stakeholders and those interested in the homeless youth population

- Based on findings and the results of this study, a general outline will be developed in which OT's can use in the youth shelter.

\section{Project Analysis}

Two research questions support this qualitative research study: (1) What are the most frequent occupational performance problems for youth in homeless shelters? And (2) What is the most frequent occupational dysfunction for youth in a homeless shelter?

The student investigator hypothesized that the most frequent occupational performance measures would consist of low perception on performance of meaningful task, and the most frequent occupational dysfunction for youth in a homeless shelter would be occupational deprivation based on literature. After the collection of data, and further analysis the hypotheses were proven to be true. The student investigator was able to identify themes based on the data collected from the COPM and the modified occupational dysfunction survey. The following section will outline the data analysis, and derived themes. 


\section{Data Analysis}

Data analysis consisted of collecting data through the COPM, MODS survey and observations.

The data was then analyzed using survey monkey and transcribed using Microsoft excel sheets.

Sociodemographic information was collected of the youth that were in the shelter to observe any correlation between sex and age of the youth.

\section{Table 2}

Sociodemographic of Youth in a Shelter
ID: $\quad$ ID 1
ID 2
ID 3
ID4
ID 5

Baseline characteristic

\begin{tabular}{|c|c|c|c|c|c|}
\hline Age & 15 & 15 & 17 & 15 & 15 \\
\hline Gender & Male & Female & Female & Female & Female \\
\hline Ethnicity & Hispanic & AA/Black & AA/Black & AA/Black & AA/Black \\
\hline Grade Level & $10^{\text {th }}$ & $10^{\text {th }}$ & $11^{\text {th }}$ & $9^{\text {th }}$ & $10^{\text {th }}$ \\
\hline \multirow[t]{2}{*}{$\begin{array}{l}\text { Employed } \\
\text { prior to shelter }\end{array}$} & Yes & No & Yes & No & No \\
\hline & ): $I D 6$ & ID 7 & $I D 8$ & ID 9 & ID 10 \\
\hline
\end{tabular}

Baseline characteristic

$\begin{array}{lrrrrr}\text { Age } & 16 & 13 & 17 & 14 & 13 \\ \text { Gender } & \text { Male } & \text { Male } & \text { Male } & \text { Male } & \text { Female }\end{array}$




\begin{tabular}{|c|c|c|c|c|c|}
\hline Ethnicity & White & AA/Black & AA/Black & White & AA/Black \\
\hline Grade Level & $11^{\text {th }}$ & $10^{\text {th }}$ & $11^{\text {th }}$ & $9^{\text {th }}$ & $8^{\text {th }}$ \\
\hline $\begin{array}{l}\text { Employed } \\
\text { prior to shelter }\end{array}$ & No & No & Yes & No & No \\
\hline
\end{tabular}

\section{Baseline} characteristic

\begin{tabular}{|c|c|}
\hline Age & 9 \\
\hline Gender & Male \\
\hline Ethnicity & White \\
\hline Grade Level & N/A \\
\hline $\begin{array}{l}\text { Employed } \\
\text { prior to shelter }\end{array}$ & No \\
\hline
\end{tabular}

\section{Research Question 1}

What are the most frequent occupational performance problems for youth in homeless shelters? Occupational performance varied depending on a variety of factors such as age and sex. The most common occupational performance problems were in the areas of productivity and leisure, according to COPM results.

Figure 1Performance Deficits 


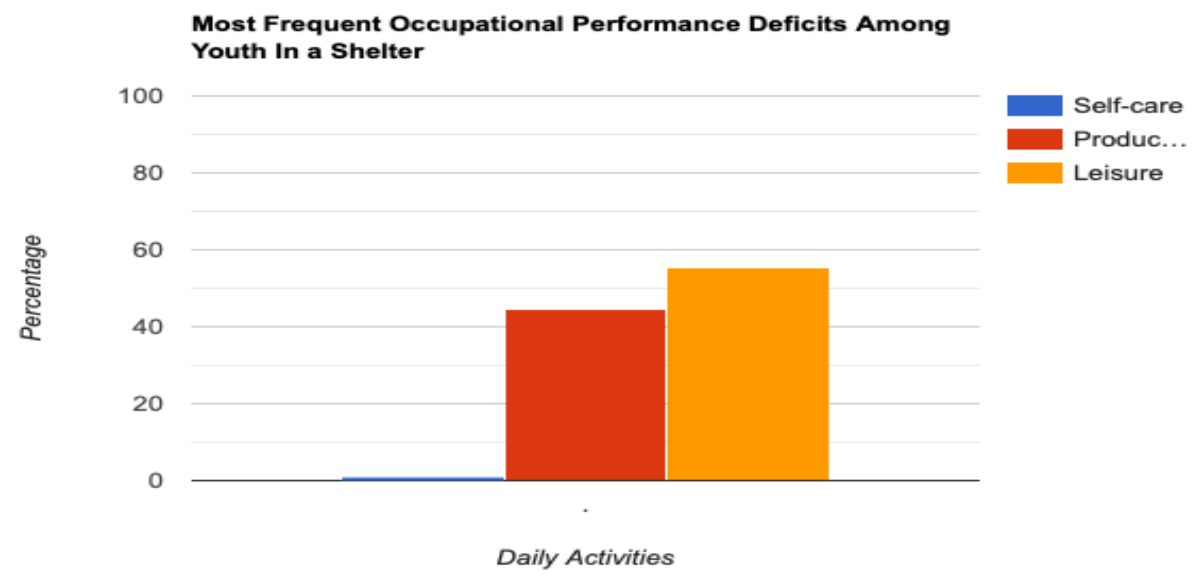

According to the COPM the youth in the shelter wished to engage in more leisure activities. These activities more common than others consisted of quiet recreation, and socialization. One youth mentioned that they could not read the books they liked because they were not available at the shelter. Another youth mentioned that while in the shelter they were only allowed one phone call a week and that cell phones were not allowed at the shelter, so they were not allowed to talk to their friends. One should take into consideration that certain rules at the shelter are put into place for the protection of the youth.

Productivity is another performance issue identified by the COPM. The areas of paid and unpaid work, and play and school, showed the most deficits. Many of the youth are not sure as to what they want to be when they grow up, and those that do have no idea on how to reach their goal. Certain professions require one to go to college, while over $50 \%$ of the youth that participated in the COPM expressed no interest in college.

\section{Research Question 2}

What is the most frequent occupational dysfunction for youth in a homeless shelter? The themes include occupational marginalization, occupational imbalance, occupational alienation, and occupational deprivation. The most common dysfunction identified was occupational deprivation. 


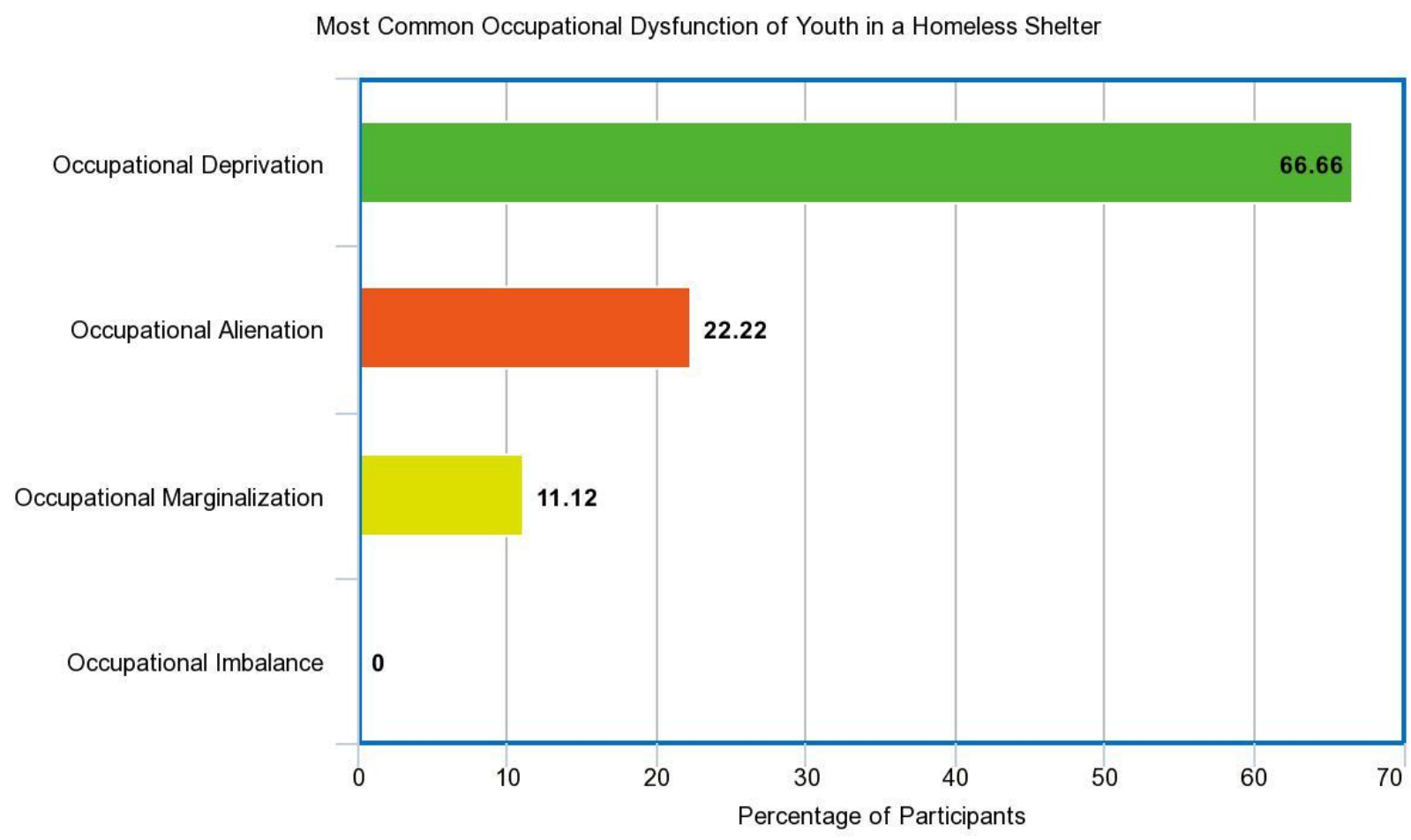

Occupational Dysfunction

After analyzing the data from the modified occupational dysfunction survey the most common occupational dysfunction among the youth in the shelter was occupational deprivation. The data showed an overwhelming response to youth not being able to complete schoolwork because they had to focus on other areas such as taking care of family members, or there was not anyone at home to help them complete it. The data also showed that youth were not able to complete occupations meaningful to them due to a mental and sometimes physical impairment. Due to a lack of knowledge of resources and in some cases access to resources, many of these youth face occupational injustices in and out of the shelter depriving them of occupations.

\section{Conclusions}

The data collected and analyzed has allowed for the student investigator to answer the following research questions: What are the most frequent occupational performance problems for youth in homeless shelters? What is the most frequent occupational dysfunction for youth in a 
homeless shelter? The COPM, modified occupational dysfunction survey, and observations have provided in dept information on the occupational performance and occupational dysfunctions of youth in a homeless shelter. The data showed that the most frequent occupational performance problems were with productivity and leisure. Productivity accounted for over $40 \%$ of occupational performance problems, while leisure accounted for over $50 \%$ of occupational performance problems. The most frequent occupational dysfunction identified based on the data is occupational deprivation. Over $60 \%$ are deprived of occupations, over $22 \%$ experience occupational alienation, and $11.2 \%$ experience occupational marginalization.

By completing the learning objectives, to identify the role of occupational therapist in youth shelters, explore the barriers to OT services, identify what skills would benefit youth in shelters the most, and serve as a template for future program development have been met. The student investigator was then able to use the data and information to define and explore the role of occupational therapist in homeless youth shelters. All data contributing to the identification of the role of OT are in this chapter to provide all stake holders with information to better serve their target population. Based on the results of this qualitative research study, the role of occupational therapists in homeless youth shelters has been identified. The information gathered can now be used as an outline for future program implementation. 


\section{Chapter V: Summary, Conclusions, and Discussions}

The purpose of this capstone project was to identify the role of occupational therapist in homeless youth shelters, by measuring the occupational performance and the occupational dysfunctions of the youth in the shelter. There is limited research on the role of occupational therapist in youth homeless shelters. Few studies have identified the occupational needs of youth in a homeless shelter. It is reported through AOTA workforce survey (2019) that $2 \%$ of OTs work in community practice which includes youth homeless shelters. This project was pursued by the student investigator because there is a gap in research on the role of occupational therapist working in homeless youth shelters. Barriers to OT intervention were explored, such as funding and knowledge of the profession.

This study was completed in 14 weeks. The participants were recruited from a homeless youth shelter in the southeast region of the United States. Data was collected from the COPM, MODS and observation of daily activities in the shelter. Barriers to OT intervention in youth shelters were also explored. The COPM is a standard assessment with a standardized way of scoring. The MODS data was analyzed through survey monkey to evaluate the most common occupational dysfunctions in homeless youth.

\section{Interpretation of Results}

The findings from this study agree with the findings from the literature review that youths in homeless shelters present with occupational performance problems and dysfunctions.

The study answered the following questions:

1.) What are the most frequent occupational performance problems for youth in homeless shelters?

2.) What is the most frequent occupational dysfunction for youth in a homeless shelter? 


\section{Research Question One}

The purpose of research question one was to identify the occupational performance problems in homeless youth. By measuring the youth performance in occupations, their performance problems were identified. The student investigator hypothesized that out of the three performance measures in the COPM, self-care, productivity, and leisure, the most common performance measure would be leisure. Within leisure there are three subcategories, socialization, active recreation, and quiet recreation, in which the student hypothesized socialization as the most frequent subcategory. According to literature homeless youth have interpersonal difficulties and high emotion regulation of trauma and subsequent mental health problems (Winiarski, 2021). Individual life experiences have all contributed to occupational performance problems.

\section{Research Question Two}

The purpose of this research question was to identify the most frequent occupational dysfunction among homeless youth. The student investigator hypothesized that the most frequent occupational dysfunction is occupational deprivation. Literature on the occupational dysfunctions of homeless youth in shelters is limited but based on a few studies and the results of the study the student hypothesis was correct. Occupational deprivations effect inter-relationships of structural factors and contextual factors support or restrict occupational outcomes and occupational rights (Townsend, E. A. 2012). A common theme that developed from this research question, is that there is a link between the occupational injustices a homeless youth may face with everyday occupations. 


\section{Strengths and Limitations}

There were several strengths and limitations in this capstone project. The strengths of this project include: The validity of the COPM, the development of the MODS, and exploration of barriers to OT intervention through dialog and observation. The COPM is a standardized assessment used to measure occupational performance. The MODS combines elements of a standardized assessment and scale, used to assess occupational dysfunctions and individual capabilities with life skills. The research collected from dialog and observation is another strength as it was received from shelter staff and supervisors.

The limitations included: the number of participants, the changing dynamics of the shelter, and COVID-19 restrictions. Initially there 12 youth who living in the shelter, by the completion of the study, there were only 9 . The dynamics of the shelter was constantly changing. None of the kids that lived in the shelter by the completion of the study, were there in the beginning. This was due to different length of stays for everyone. COVID-19 played a role as to when the study could begin. Clearance from the shelter supervisor and a PCR COVID-19 test were required before the study could begin.

\section{Recommendations for the Future}

Recommendations for the future project exploration is to complete all elements of this study at numerous shelters. This will increase the data pool and will allow for variability in different settings. There may be different barriers to OT intervention in different settings, affecting the role of OT to be defined. By carrying out all elements of this study in numerous shelters, the occupational performance and dysfunction findings would be drawn from a larger scale. In future studies a survey should be developed for the staff of the shelter to have recorded and sound evidence on what the role of OTs is in youth shelters. The findings in this study could 
also be used as a guide for future program development in a youth shelter, addressing occupational performance and dysfunctions among youth. Another theoretical model that could also be explored is the model of human occupations (MOHO), which describes how humans generate and modify their occupations in interaction with environment, which presents a dynamic open cycle system of human actions (Kielhofner, G., et al, 1980).

\section{Conclusion}

This qualitative research study concludes that there is a need for OTs in homeless youth shelters, and that their role is to improve the occupational performance and dysfunctions of the youth. The COPM and MODS can be used to measure and identify occupational performance and dysfunctions of youth. There are barriers to OT interventions such as a lack of funding and a general knowledge of the OT profession. This paper supports that OTs should play an active role in the development of skills in youth living in a shelter. The role of occupational therapy is to establish or re-establish occupations (Schultz-Krohn., et al, 2018). 


\section{References}

Abaoğlu, H., Cesim, Ö B., Kars, S., \&Çelik, Z. (2017). Life skills in occupational therapy. Occupational Therapy - Occupation Focused Holistic Practice in Rehabilitation. DOI: $10.5772 /$ intechopen.68462

Adrienne L. Fernandes-Alcantara. (2019). Congressional Research Service. Runaway and Homeless Youth: Demographics and Programs. https://crsreports.congress.gov/product/pdf/RL/RL33785.

American Institutes for Research. (2014). America's youngest outcasts: A report card on child homelessness. Retrieved from https://www.air.org/sites/default/ files/downloads/report/Americas-Youngest-Outcasts-Child-Homeless- ness-Nov2020pdf

American Occupational Therapy Association. (2014). Occupational therapy practice framework: Domain and process (3rd ed.). American Journal of Occupational Therapy, 68(Suppl. 1), S1-S48. http://doi.dx.org/10.5014/ajot.2014.682006

Auerswald, C. L., \& Adams, S. (2018). Counting All Homeless Youth Today So We May No Longer Need To Tomorrow. Journal of Adolescent Health,62(1), 1-2. doi:10.1016/j.jadohealth.2017.10.013

Aviles, A., \& Helfrich, C. (2004). Life Skill Service needs: Perspectives of homeless Youth. Journal of Youth and Adolescence,33(4), 331-338. https://DOI: 10.1023/B:JOYO.0000032641.82942.22 
Barnes, A. J., Gower, A. L., Sajady, M., \& Lingras, K. A. (2020). Health and Adverse Childhood Experiences Among Homeless Youth.doi:10.21203/rs.2.24424/v1

Bender, K., Ferguson, K., Thompson, S., Komlo, C., \& Pollio, D. (2010). Factors associated with trauma and posttraumatic stress disorder among homeless youth in three U.S. cities: The importance of transience. Journal of Traumatic Stress,23(1), 161-168.

\section{https://doi.org/10.1002/jts.20501}

Black, E. B., Fedyszyn, I. E., Mildred, H., Perkin, R., Lough, R., Brann, P., \& Ritter, C. (2018). Homeless youth: Barriers and facilitators for service referrals. Evaluation and Program Planning,68, 7-12. https://doi.org/10.1016/j.evalprogplan.2018.02.009

Brothers, S., Lin, J., Schonberg, J., Drew, C., \& Auerswald, C. (2020). Food insecurity among formerly homeless youth in supportive housing: A social-ecological analysis of a structural intervention. Social Science \& Medicine,245, 112724. doi:10.1016/j.socscimed.2019.112724

Burke, C. W., Firmin, E. S., Ducharme, P., \& Wilens, T. E. (2020). 48.4 Prevalence, Comorbidity, And Psychosocial Correlates Of Psychopathology And Substance Use Disorders Among Homeless Transitional-Age Youth: Preliminary Findings. Journal of the American Academy of Child \& Adolescent Psychiatry,59(10).

doi:10.1016/j.jaac.2020.08.390 
Canadian Association of Occupational Therapists. (2002). Enabling occupation: An occupational therapy perspective (rev. ed.). CAOT Publications ACE.

Chapleau, A., Seroczynski, A. D., Meyers, S., Lamb, K., \&Buchino, S. (2012). The effectiveness of a consultation model in community mental health. Occupational Therapy in Mental Health, 28, 379-395.

Christiani, A., Hudson, A. L., Nyamathi, A., Mutere, M., \& Sweat, J. (2008). Attitudes of Homeless and Drug-Using Youth Regarding Barriers and Facilitators in Delivery of Quality and Culturally Sensitive Health Care. Journal of Child and Adolescent Psychiatric Nursing, 21(3), 154-163. https://doi.org/10.1111/j.1744-6171.2008.00139.x

Cole, M. B. (2018). Group Dynamics in Occupational Therapy: The Theoretical Basis and Practice Application of Group Intervention. Slack.

Colver, A., Rapley, T., Parr, J. R., Mcconachie, H., Dovey-Pearce, G., Couteur, A. L., .. . Vale, L. (2019). Facilitating the transition of young people with long-term conditions through health services from childhood to adulthood: The Transition research programme. Programme Grants for Applied Research,7(4), 1-244. doi:10.3310/pgfar07040

Cunningham, M. J., \& Slade, A. (2017). Exploring the lived experience of homelessness from an occupational perspective. Scandinavian Journal of Occupational Therapy,26(1), 19-32. doi:10.1080/11038128.2017.1304572 
Daining, C., \& DePanfilis, D. (2007). Resilience of youth in transition from out-of-home care to adulthood. Children and Youth Services Review, 29, 1158-1178. https://doi.org/10.1016/j.childyouth.2007.04.006

Davies, B. R., \& Allen, N. B. (2017). Trauma and homelessness in youth: Psychopathology and intervention. Clinical Psychology Review, 54, 17-28. https://doi.org/10.1016/j.cpr.2017.03.005

Davis-Worden, D. (2017). Occupational Therapy Services in Homeless Programs. An Innovative Practice in VHA Homeless Program Operations.

Dawsn-Rose, C., Shehadeh, D., Hao, J., Barnard, J., Khoddam-Khorasani, L. (., Leonard, A., Cuca, Y. P. (2020). Trauma, substance use, and mental health symptoms in transitional age youth experiencing homelessness. Public Health Nursing,37(3), 363-370. https://doi.org/10.1111/phn.12727

Durocher, E., Gibson, B. E., \& Rappolt, S. (2014). Occupational justice: A con-ceptual review. Journal of Occupational Science, 21, 418-430. https://doi.org/1 $0.1080 / 14427591.2013 .775692$

Education Counts. (n.d.). Title Retrieved June 02, 2020, from http://www.edcounts.org/createtable/step1.php

Farias, L, Laliberte-Rudman, D, Magalhaes, L (2016) Illustrating the importance of critical epistemology to realize the promise of occupational justice. Occupational Therapy Journal of Research: Occupation, Participation and Health, 36(4): 234-243. 
Federal Programs. (2010). Retrieved from https://youth.gov/youth-topics/runaway-andhomeless-youth/federal-programs

Fernandes-Alcantara, A. L. (2018, April 25). Congressional research Service. Retrieved from https://crsreports.congress.gov/

Finlayon, M., Baker, M., Rodman, L., \& Herzberg, G. (2002). The Process and Outcomes of a Multimethod Needs Assessment at a Homeless Shelter. American Journal of Occupational Therapy,56(3), 313-321. https://doi.org/10.5014/ajot.56.3.313

Florida Homelessness Statistics. (n.d.). Retrieved June 02, 2020, from https://www.usich.gov/homelessness-statistics/fl/

Grandisson, M., Mitchell-Carvalho, M., Tang, V., \& Korner-Bitensky, N. (2009). Occupational Therapists Perceptions of Their Role with People Who are Homeless. British Journal of Occupational Therapy,72(11), 491-498. DOI: $\underline{10.4276 / 030802209 X 12577616538672}$

Glumbíková, K., \& Mikulec, M. (2020). Needs of homeless children in the Czech Republic. Child \& Family Social Work,26(1), 183-190.doi:10.1111/cfs.12807

Gwadz, M., Freeman, R. M., Kutnick, A. H., Silverman, E., Ritchie, A. S., Cleland, C. M., Bolas, J. (2018). Do Programs for Runaway and Homeless Youth Work? A Qualitative Exploration From the Perspectives of Youth Clients in Diverse Settings. Frontiers in Public Health,6. doi: 10.3389/fpubh.2018.00112

Heinze, H. J., \& Jozefowicz-Simbeni, D. M. (2009). Intervention for homeless and at-risk youth: Assessing youth and staff perspectives on service provision, satisfaction and 
quality. Vulnerable Children and Youth Studies,4(3), 210-225. https://doi.org/10.1080/17450120902890578

Helfrich, C. A., Aviles, A. M., Badiani, C., Walens, D., \& Sabol, P. (2006). Life Skill Interventions with Homeless Youth, Domestic Violence Victims and Adults with Mental Illness. Occupational Therapy In Health Care,20(3-4), 189-207. https://doi.org/10.1080/J003v20n03_12

Hodgson, K. J., Shelton, K. H., Bree, M. B., \& Los, F. J. (2013). Psychopathology in Young People Experiencing Homelessness: A Systematic Review. American Journal of Public Health, 103(6). https://doi.org/10.2105/AJPH.2013.301318

Homelessness in America. (n.d.). Retrieved June 02, 2020, from https://nationalhomeless.org/about-homelessness/

How Long Can You Stay at a Homeless Shelter? (2019, February 20). Retrieved from https://www.streetworksmn.org/how-long-can-you-stay-at-a-homeless-shelter/

Huang, Sabrina. "Policy inconsistency leaves youth experiencing homelessness behind." UWIRE Text, 6 Jan. 2020, p. 1. Gale Academic OneFile Select, link.gale.com/apps/doc/A610751075/EAIM?u=lirn55718\&sid=bookmarkEAIM\&xid=795bd76d. Accessed 15 Aug. 2021.

Hughes, J. R., Clark, S. E., Wood, W., Cakmak, S., Cox, A., Macinnis, M., Warren, B., Handrahan, E., \& Broom, B. (2010). Youth Homelessness: The Relationships among Mental Health, Hope, and Service Satisfaction. Journal of the Canadian Academy of 
Child and Adolescent Psychiatry = Journal de l'Academiecanadienne de psychiatrie de l'enfant et de l'adolescent, 19(4), 274-283.

Hungaro, A. A., Gavioli, A., Christóphoro, R., Marangoni, S. R., Altrão, R. F., Rodrigues, A. L., \& Oliveira, M. L. (2020). Homeless population: Characterization and contextualization by census research. Revista Brasileira De Enfermagem,73(5). doi:10.1590/0034-71672019-0236

Hutton, L. (2018, April 03). An Age-by-Age Guide to Teaching Your Child Life Skills. Retrieved November 07, 2020, from https://www.familyeducation.com/life/individuality/guide-to-teach-your-child-life-skillsby-age

Jeanis, M. N., Fox, B. H., \& Muniz, C. N. (2018). Revitalizing Profiles of Runaways: A Latent Class Analysis of Delinquent Runaway Youth. Child and Adolescent Social Work Journal,36(2), 171-187. doi:10.1007/s10560-018-0561-5

Kielhofner, G., \& Burke, J. P. (1980). A model of human occupation, part 1. Conceptual framework and content. American Journal of Occupational Therapy, 34, 572-581.

Khezri, M., Mirzazadeh, A., Mcfarland, W., Iranpour, A., Shahesmaeili, A., Zarei, J., ... Sharifi, H. (2020). Prevalence of substance use and associated risk factors among homeless youth in Iran: A cross-sectional study. Children and Youth Services Review, 116, 105070. doi:10.1016/j.childyouth.2020.105070 
Law, M., Cooper, B,. Strong, S., Stewart, D., Rigby, P. \& Letts, L. 1996. The PersonEnvironment-Occupation Model: A transactive approach to occupational performance. Canadian Journal of Occupational Therapy. 63(1):9-23.

Lauckner, H., Pentland, W., \& Paterson, M. (2007). Exploring Canadian Occupational Therapists Understanding of and Experiences in Community Development. Canadian Journal of Occupational Therapy,74(4), 314-325. DOI: $\underline{10.2182 / \text { cjot.07.005 }}$

Life skills. (n.d.). Retrieved November 08, 2020, from https://www.unicef.org/topics/life-skills

Lloyd, C., \& Bassett, H. (2012). The role of occupational therapy in working with the homeless population: An assertive outreach approach. New Zealand Journal of Occupational Therapy, 59(1), 18-23.

Malfitano, APS, de Souza, RGM, Lopes, RE (2016) Occupational justice and its related concepts: An historical and thematic scoping review. Occupational Therapy Journal of Research: Occupation, Participation and Health 36(4): 167-178

McCann, M. (2019, June 18). Youth Homeless Overview. Retrieved from https://www.ncsl.org/research/human-services/homeless-and-runaway-youth.aspx

Mehmandoost, S., Mirzazadeh, A., Zarei, J., Iranpour, A., Mousavian, G., Khezri, M., .. . Sharifi, H. (2021). Sex out of marriage and condom use among homeless youth in Iran. Public Health,194, 116-120. doi:10.1016/j.puhe.2021.02.021

Mental Health.gov. (n.d.). Retrieved November 07, 2020, from https://www.mentalhealth.gov/ 
Merritt, J., \& Benningfield, M. (2019). Lessons From the Street Through a Homeless Youth With Depression. Psychiatric Services,70(6), 526-527.doi:10.1176/appi.ps.70601

Morewitz, S. J. (2016). Runaway and Homeless Youth Interventions. Runaway and Homeless Youth,209-218. doi:10.1007/978-3-319-30863-0_20

Minnery, J., \& Greenhalgh, E. (2007). Approaches to Homelessness Policy in Europe, the United States, and Australia. Journal of Social Issues, 63(3), 641-655. DOI:10.1111/J.1540$\underline{4560.2007 .00528 . X}$

Mirriam-Webster. (2014). Websters dictionary of the English language. Fort Wayne, IN.

Murtagh, L., Lloyd, C., \& Bassett, H. (2010). The role of an Australian homeless health outreach team. Part 2: A case study. International Journal of Therapy and Rehabilitation,17(8), 436-443. DOI: $\underline{10.12968 / 1 j \operatorname{tr} .2010 .17 .8 .49292}$

Miyake, Y., Eguchi, E., Ito, H., Nakamura, K., Ito, T., Nagaoka, K., . . Ogino, K. (2018). Association between Occupational Dysfunction and Metabolic Syndrome in CommunityDwelling Japanese Adults in a Cross-Sectional Study: Ibara Study. International Journal of Environmental Research and Public Health,15(11), 2575. doi:10.3390/ijerph15112575

NAEH. National Alliance to End Homelessness (2020, November 06). Retrieved November 08, 2020, from https://endhomelessness.org/

NAMI: National Alliance on Mental Illness. (n.d.). Retrieved from https://www.nami.org/home?gclid=CjwKCAjw092IBhAwEiwAxR11Rrrr85_zEL9ozJac $\underline{\text { AMgVI2q3DP2ZuRwJPgDFUWLzbGH4TKV_g8S6gBoC_9sQAvD_BwE }}$ 
O’Brien, J. R., Edinburgh, L. D., Barnes, A. J., \& Mcree, A. (2020). Mental Health Outcomes Among Homeless, Runaway, and Stably Housed Youth. Pediatrics, 145(4). doi:10.1542/peds.2019-2674

Occupational deprivation. (n.d.) Medical Dictionary. (2009). Retrieved July 242021 from https://medical-dictionary.thefreedictionary.com/occupational+deprivation

Oss, T. V., Duch, F., Frank, S., \& Laganella, G. (2020). Identifying occupation-based needs and services for individuals experiencing homelessness using interviews and photovoice. Work,65(2), 247-255. DOI: 10.3233/WOR-203076

Parry, B. J., Quinton, M. L., Holland, M. J., Thompson, J. L., \& Cumming, J. (2021). Improving outcomes in young people experiencing homelessness with My Strengths Training for Life $^{\mathrm{TM}}$ (MST4Life ${ }^{\mathrm{TM}}$ ): A qualitative realist evaluation. Children and Youth Services Review,121, 105793.doi:10.1016/j.childyouth.2020.105793

Paul-Ward, A., \& Lambdin-Pattavina, C. A. (2016). New Roles for Occupational Therapy to Promote Independence Among Youth Aging Out of Foster Care. American Journal of Occupational Therapy,70(3)._doi:10.5014/ajot.2016.017426

Pedersen, E. R., Tucker, J. S., \& Kovalchik, S. A. (2016). Facilitators and Barriers of Drop-In Center Use Among Homeless Youth. Journal of Adolescent Health,59(2), 144-153. doi:10.1016/j.jadohealth.2016.03.035 
Roy, L., Vallée, C., Kirsh, B. H., Marshall, C. A., Marval, R., \& Low, A. (2017). Occupationbased practices and homelessness: A scoping review. Canadian Journal of Occupational Therapy, 84(2), 98-110. doi:10.1177/0008417416688709

Schultz-Krohn, W., \& Tyminski, Q. (2018). Community-Built Occupational Therapy Services for Those Who Are Homeless. Community-Built Occupational Therapy Services for Those Who Are Homeless, 1-9. Retrieved July 22, 2021.

Semmelhack, E., Simpson, E., Conniff, B., \& Faber, B. (2019). Young People's Experiences of Homelessness and Its Influence on Their Daily Routines and Occupational Participation. American Journal of Occupational Therapy,73(4_Supplement_1). https://doi.org/10.5014/ajot.2019.73S1-2019Abstrintro

Simpson, E. K., Mcdermott, C. P., \& Hild, L. E. (2020). Needs of Transitionally Housed Young People to Promote Occupational Participation. Occupational Therapy In Health Care,34(1), 62-80. doi:10.1080/07380577.2020.1737895

Slesnick, N., Kang, M. J., Bonomi, A. E., \& Prestopnik, J. L. (2007). Six- and Twelve-Month Outcomes among Homeless Youth Accessing Therapy and Case Management Services through an Urban Drop-in Center. Health Services Research,43(1p1), 211-229. DOI: $\underline{10.1111 / \mathrm{j} .1475-6773.2007 .00755 . \mathrm{x}}$

Strong, S., Rigby, P., Stewart, D., Law, M., Letts, L., \& Cooper, B. (1999). Application of the Person-Environment-Occupation Model: A practical Tool. Canadian Journal of Occupational Therapy,66(3), 122-133. doi:10.1177/000841749906600304 
Substance Abuse and Mental Health Services Administration. (2016). Youth. Retrieved from http://www.samhsa.gov/homelessness-programs-resources/hpr-resources/youth

Swift, J. (2020, October 20). Youth Homelessness: The Facts. Retrieved November 07, 2020,from https://www.kuc.org.au/library/youth-homelessness-the-facts/

Synovec, C. E., Merryman, M., \& Brusca, J. (2020). Occupational Therapy in Integrated Primary Care: Addressing the Needs of Individuals Experiencing Homelessness. The Open Journal of Occupational Therapy,8(4), 1-14. doi:10.15453/2168-6408.1699

The Oxford dictionary. (1992). Oxford: Oxford University Press.

Teraoka, M., \& Kyougoku, M. (2015). Development of the Final Version of the Classification and Assessment of Occupational Dysfunction Scale. Plos One, 10(8). doi:10.1371/journal.pone.0134695

Thomas, Y., Gray, M., \& Mcginty, S. (2010). A Systematic Review of Occupational Therapy Interventions With Homeless People. Occupational Therapy In Health Care,25(1), 3853. https://doi.org/10.3109/07380577.2010.528554

Townsend, E., \& A.wilcock, A. (2004). Occupationaljustice and Client-Centred Practice: A Dialogue in Progress. Canadian Journal of Occupational Therapy,71(2), 75-87. doi:10.1177/000841740407100203

Teen Homelessness Statistics. (2021). Retrieved from https://www.covenanthouse.org/homeless$\underline{\text { teen-issues/statistics }}$ 
US Department of Housing and Urban Development. (2019). AHAR reports. Retrieved July 5, 2019, from https://www.hudexchange.info/homelessness-assistance/ahar

U.S. Department of Housing and Urban Development. (2017). The 2017 Annual Homeless Assessment Report (AHAR) to Congress. Retrieved from https://www.hudexchange.info/resources/documents/2017-AHAR-Part-1.pdf

Van Oss, T., Condoluci, S., \& Annino, R. (2018). Homelessness and the role of occupational therapy. SIS Quarterly Practice Connections, 3(2), 11-13.

Wang, J. Z., Mott, S., Magwood, O., Mathew, C., Mclellan, A., Kpade, V., . . Andermann, A. (2019). The impact of interventions for youth experiencing homelessness on housing, mental health, substance use, and family cohesion: A systematic review. BMC Public Health,19(1). doi:10.1186/s12889-019-7856-0

Weisen RB, Orley J, Evans V, Jeff Lee T, Sprunger B, Pellaux D. Life Skills Education in Schools. Geneva, Switzerland: World Health Organization; 1994

Why Do Young People Become Homeless in America? (2017, March 12). Retrieved from https://nn4youth.org/learn/why-homeless/

Whyte, A. (2019, November 24). Homeless Youth: Increased Risk of Mental Health Disorders. Retrieved from https://evolvetreatment.com/blog/homeless-youth-mental-illness/

Williams, A., Giano, Z., \& Merten, M. (2019). Running away during adolescence and future homelessness: The amplifying role of mental health. American Journal of Orthopsychiatry,89(2), 268-278. doi:10.1037/ort0000397 
Winiarski, D. A., Glover, A. C., Bounds, D. T., \& Karnik, N. S. (2021). Addressing Intersecting Social and Mental Health Needs Among Transition-Age Homeless Youths: A Review of the Literature. Psychiatric Services, 72(3), 317-324. doi:10.1176/appi.ps.201900498

Winiarski, D. A., Rufa, A. K., Bounds, D. T., Glover, A. C., Hill, K. A., \& Karnik, N. S. (2020). Assessing and treating complex mental health needs among homeless youth in a shelterbased clinic. BMC Health Services Research,20(1). https://doi.org/10.1186/s12913-020$\underline{4953-9}$

Wong, C., \& Leland, N. E. (2018). Applying the Person-Environment-Occupation Model to Improve Dementia Care. Aota Continuing Education. Retrieved from https://www.aota.org/ /media/Corporate/Files/Publications/CE-Articles/CE-Article-May18.pdf.

World Health Organization. (n.d.). Retrieved June 02, 2020, from https://www.who.int/

Yarcusko, E., Slesnick, N., \& Hatsu, I. (2019). Food Sources for Homeless Youth: An Evaluation of Food Availability at a Homeless Youth Drop-In Center. Journal of Nutrition Education and Behavior,51(1), 91-95. doi:10.1016/j.jneb.2018.08.010

Yoshioka-Maxwell, A., \& Rice, E. (2020). Exploring the relationship between foster care experiences and social network engagement among a sample of homeless former foster youth. Children and Youth Services Review, 116, 105132.

10.1016/j.childyouth.2020.105132

Youth.GOV. (2011). Federal definitions. Retrieved from https://youth.gov/youth$\underline{\text { topics/runaway-and-homeless-youth/federal-definitions }}$ 


\section{Appendices}

\section{Appendix A}

\section{IRB Approval Letter}

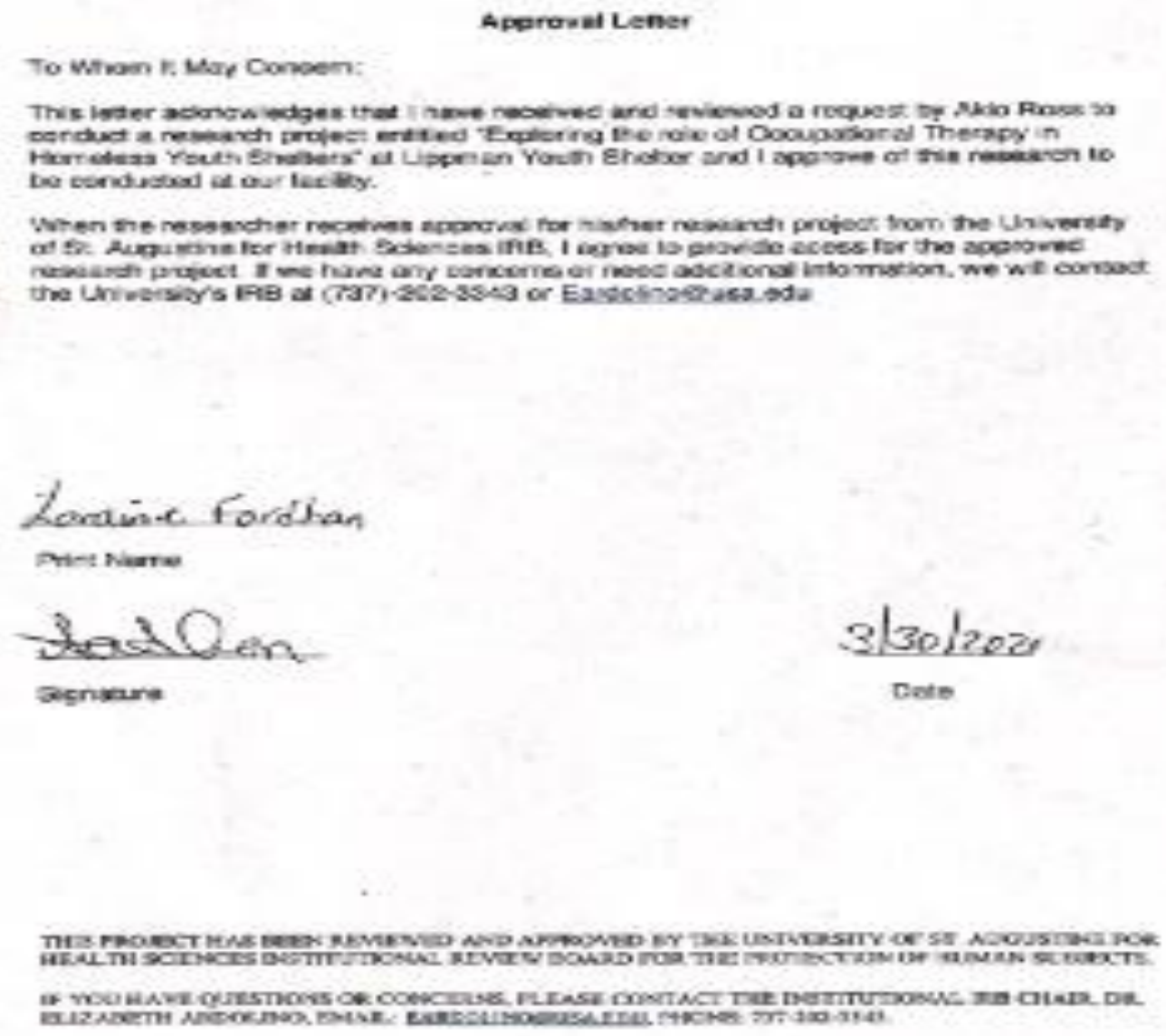


Appendix B

\section{Recruitment Script}

"Hello, my name is Akio Ross. I am an occupational therapy doctorate student at the USAHS. I am competing a research study as part of my OTD curriculum. I am inviting you to participate in a research study exploring the role of OT in homeless youth shelters. Participation in this research study involves completing an interview with the student investigator which will take approximately 15-30 minutes dependent on participant responses. "If you have any further questions or would like to participate I can be reached at (a.ross2@usa.edu and 954-638-1593). I look forward to hearing from you.

THIS PROJECT HAS BEEN REVIEWED AND APPROVED BY THE UNIVERSITY OF ST. AUGUSTINE FOR HEALTH SCIENCES INSTITUTIONAL REVIEW BOARD FOR THE PROTECTION OF HUMAN SUBJECTS.

IF YOU HAVE QUESTIONS OR CONCERNS, THOSE QUESTIONS OR CONCERNS SHOULD BE DIRECTED TO THE INSTITUTIONAL IRB CHAIR, DR. ELIZABETH ARDOLINO, EMAIL: EARDOLINO@USA.EDU, PHONE: 737-202-3343 
Appendix C

Informed Consent

\section{$\underline{\text { IRB }}$}

University of St. Augustine for Health Sciences

Out of town: 1-855-384-9965 x3270; Local Texas \#: 1-737-202-3270 x3270

IRB Informed Consent Form, IRB \# _-

\section{CONSENT FOR RESEARCH PARTICIPATION \\ Parent/Legal Guardian/LAR Permission}

Title of Project: Exploring the Role of Occupational Therapy in Homeless Youth Shelters

Principal Investigator:

Name: Dr. Pamela Kasyan-Howe, Doctoral Coordinator

Phone Number: 305-992-1410

Email: pkasyanhowe@usa.edu

Student Investigator:

Name: Akio Ross, Occupational Therapy Doctorate Student

Phone Number: 954-638-1593

Email:a.ross2@usa.edu

\section{Overview}

We are asking you to allow your child/ward to be in a research study. A research study is an organized way of collecting information about scientific questions. This form will tell you what you and your child/ward should expect if you agree to allow your child/ward to be in the study. There are programs in place to make sure that investigators fulfill their obligations listed in this form.

The box below highlights key information about this research for you to consider when making a decision whether or not to participate. Carefully consider this information and the more detailed information provided below the box. Please ask questions about any of the information you do not understand before you decide whether to participate.

\section{Key Information for You to Consider}

Voluntary Consent. Your child/ward is being asked to volunteer for a research study to explore the role of occupational therapy in homeless youth shelters. It is up to you whether they can participate or not. There will be no penalty or loss of benefits to which you are otherwise entitled if you choose for them to not participate or discontinue participation. 
Purpose. The purpose of this generic qualitative research project is to explore the occupational performance and occupational deprivation experienced by youth in homeless shelters. A better understanding of the activities that are available, as compared to restricted activities will improve the understanding of the occupational dysfunction of the population. A better understanding of the occupational dysfunction will provide for the opportunity of occupational therapists and other stakeholders serving the population to provide services assisting the youth and occupational therapist in establishing goals and plans of care to address the occupational dysfunction. In return providing the population with improved occupational performance, and improved quality of life.

Duration. It is expected that your child/wards participation will take 45-60 minutes.

Procedures and Activities. Your child/ ward will be asked to answer questions regarding; What are the most frequent occupational performance problems for youth in homeless shelters? What is the most frequent occupational dysfunction for youth in a homeless shelter?

Risks. There is minimal risk involved when completing the Canadian occupational performance measure (COPM). If there is any psychological or emotional effect due to the COPM, exhibited by any of participants, the shelter psychologist will be readily available.

Benefits. The participants will receive no personal benefits other than contributing to the body of research to discover further strategies to define the role of occupational therapist in homeless youth shelters.

Alternatives Participation is voluntary, and the only alternative is to not participate.

\section{Why is this research being done?}

This research is being done to fill the gap between occupational therapy and homeless youth shelters. Little has been published about the role of occupational therapy working with the homeless (Lloyd \& Bassett, 2010; Murtagh, Lloyd, \& Bassett, 2010).

\section{What Will Happen in This Research Study?}

Your child/wards participation in this research study will consist of an in-person interview using the Canadian occupational performance measure (COPM). Participation is approximately 45-60 minutes, which will be dependent on completion time. You will be required to sign this consent form prior to the participation in this study. The youth's privacy and confidentiality are described in a separate section later in this form. Your child/ward will be one of approximately 20 subjects who will be asked to be in the study. 


\section{$\underline{\text { Risks and Discomforts }}$}

There is minimal risk involved when completing the Canadian occupational performance measure (COPM). If there is any psychological or emotional effect due to the COPM, exhibited by any of participants, the shelter psychologist will be readily available.

\section{Potential Benefits}

The participants will receive no personal benefits other than contributing to the body of research to learn importance of collaboration and communication to improve occupational performance for children with special needs.

\section{$\underline{\text { Costs }}$}

There are no costs to you or your child/ward for your child being in this research study.

\section{$\underline{\text { Payment }}$}

You and your child/ward will not be paid for being in this study.

\section{Confidentiality}

The research records will be maintained within an encrypted folder within the student investigator's personal computer. Access to the information will be limited to the student investigator (Akio Ross), and the supervisor investigator (Dr. Kasyan-Howe) he results will be stored within an encrypted folder. No information that could potentially identify you child/ward will be published. All data will be destroyed after three years following the completion of the study.

If you agree to be in the study and sign this form, we will share information that may show your child/ward's identity with the following groups of people:

- People who do the research or help oversee the research, including safety monitoring.

- People from Federal and state agencies who audit or review the research, as required by law. Such agencies may include the U.S. Department of Health and Human Services, the Food and Drug Administration, and the National Institutes of Health.

- Any people who you give us separate permission to share your child/ward's information.

We will share research data where we have removed anything that we think would show your child/ward's identity. There still may be a small chance that someone could figure out that the information is about your child/ward. Such sharing includes:

- Publishing results in a professional book or journal.

- Adding results to a Federal government database.

- Using research data in future studies, done by us or by other scientists.

\section{Subject's Rights}


By giving permission for your child/ward to be in this study, you do not waive any of your or your child/ward's legal rights. Giving permission means that you have been given information about this study and that you agree to have your child/ward participate in the study. You will be given a copy of this form to keep.

If you or your child/ward do not agree for your child/ward to be in this study or if at any time your child/ward withdraws from this study, you or your child/ward will not suffer any penalty or lose any benefits to which you or your child/ward are entitled. Your child/ward's participation is completely up to you and your child/ward. Your decision and your child/ward's decision will not affect your or your child/ward's ability to get health care or payment for your or your child/ward's health care. It will not affect your or your child/ward's enrollment in any health plan or benefits you or your child/ward can get.

\section{Questions}

The investigator or a member of the research team will try to answer all of your questions. If you have questions or concerns at any time, contact Akio Ross at 954-638-1593.

You may also call 737-202-3343 or email eardolino@usa.edu. You will be talking to Elizabeth Ardolino, the chairperson of the IRB at the University of St. Augustine for Health Sciences. The IRB is a group that helps monitor research. You should call or email the IRB if you want to find out about your rights as a research subject. You should also call or email if you want to talk to someone who is not part of the study about your questions, concerns, or problems. By agreeing for your child/ward to be in this research, you are indicating that you have read this form (or it has been read to you), that your questions have been answered to your satisfaction, and that you voluntarily agree to allow your child/ward to participate in this research study.

Child Subject:

Printed name of subject

By signing this permission form, you are indicating that

- you have read this form (or it has been read to you)

- your questions have been answered to your satisfaction

- you voluntarily agree to allow your child/ward to participate in this research study

Printed name of parent/legal guardian/LAR

Signature of parent/legal guardian/LAR

Date

(Include if any children will read the permission form (this is recommended only for children aged 16 or 17) By signing below, you are indicating that you have read this form, that your questions have been answered, and that you voluntarily agree to participate in this research study. 
Researcher:

Printed name of person conducting consent discussion

I have personally explained the research to the above-named child and to the parent/legal guardian/lar and answered all questions. I believe that they understand what is involved in the study and freely agree to participate.

Signature of person conducting consent discussion

Date

THIS PROJECT HAS BEEN REVIEWED AND APPROVED BY THE UNIVERSITY OF ST. AUGUSTINE FOR HEALTH SCIENCES INSTITUTIONAL REVIEW BOARD FOR THE PROTECTION OF HUMAN SUBJECTS.

IF YOU HAVE QUESTIONS OR CONCERNS, PLEASE CONTACT THE INSTITUTIONAL IRB CHAIR, DR. ELIZABETH ARDOLINO, EMAIL: EARDOLINO@USA.EDU, PHONE: 737-202-3343. 


\section{Appendix D}

\section{Data Collection Instrument}

\section{CANADIAN}

OCCUPATIONAL

PERFORMANCE

MEASURE

Authors:

Mary Law, Sue Baptiste, Anne Carswell, Mary Ann McColl, Helene Polatajko, Nancy Pollock

The Canadian Occupational Performance Measure (COPM) is an individualized measure designed for use by occupational therapists to detect self-perceived change in occupational performance problems over time.

Client Name:

\begin{tabular}{l|l|l}
\hline Age: & Gender: & ID\#:
\end{tabular}

Respondent (if not client):

\begin{tabular}{l|l}
\hline Date of Assessment: & Planned Date of
\end{tabular}

Date of Reassessment:

Reassessment:

Therapist:

Facility/Agency:

Program:

Published by CAOT Publications ACE

Printed in Canada

(c) M. Law, S. Baptiste, A. Carswell, M.A. McColl, H. Polatajko, N. Pollock, 2000 


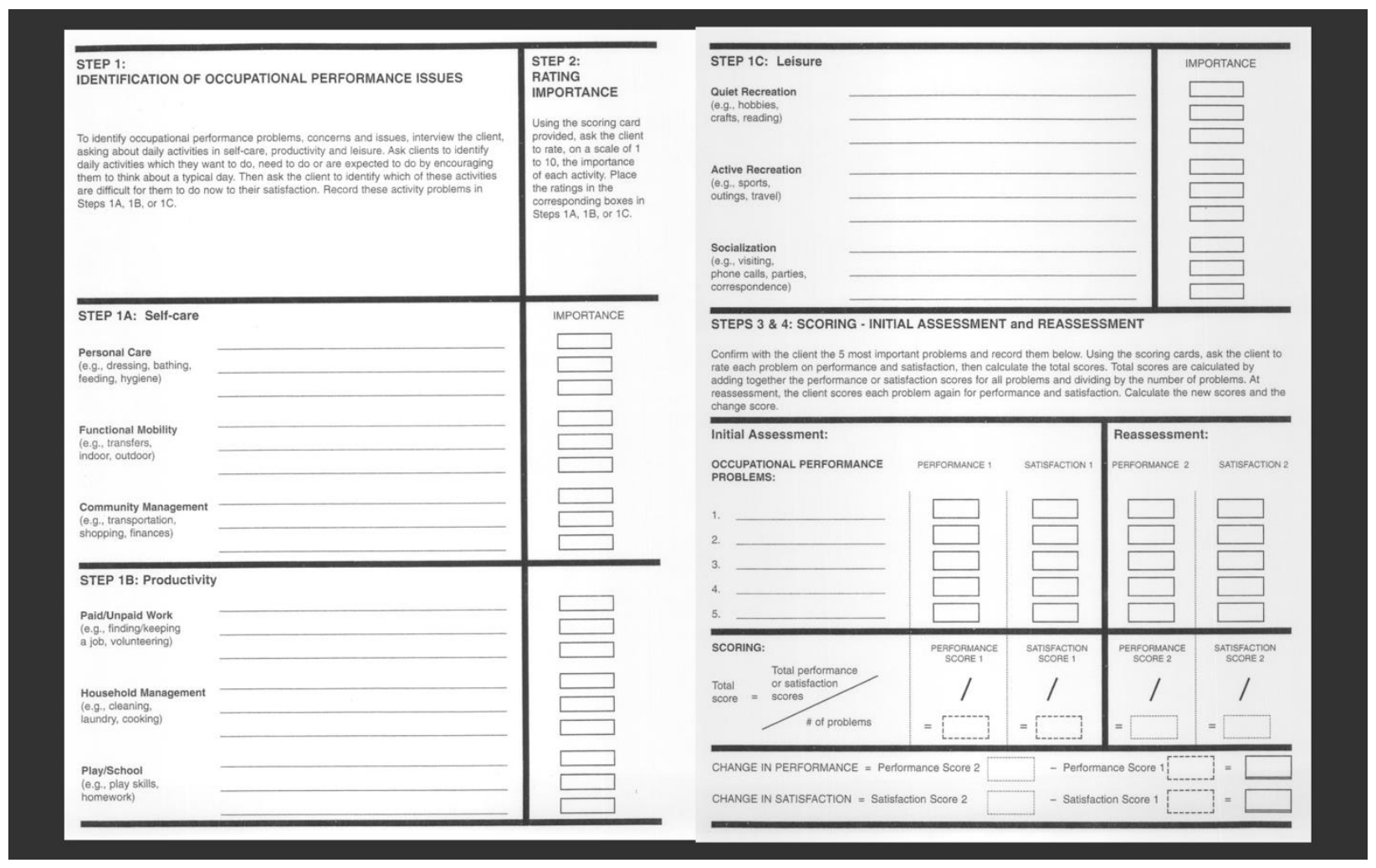


ADDITIONAL NOTES AND BACKGROUND INFORMATION

Initial Assessment: 


\section{Appendix E}

\section{THEORY OF CHANGE - TEMPLATE}

(This can be completed in the pdf)

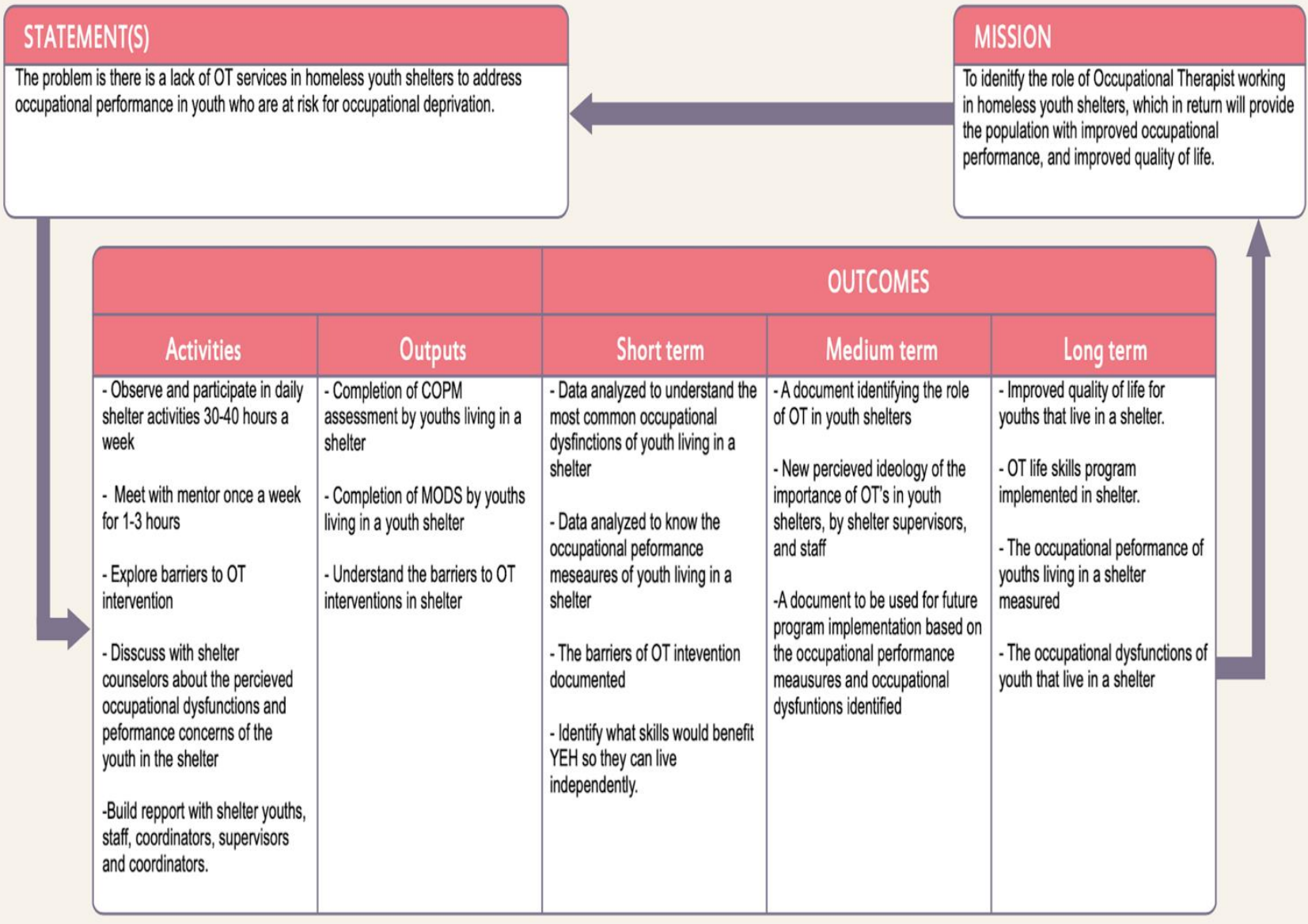

\section{KEYASSUMPTIONS}

Occupational therapists, shelter coordinators, and supervisors are unaware of the positive impact OT's can have on the development of youth in shelters across the life span. It is assumed that youth in shelters would benefit from OT intervention to transition into the community. It is also assumed that the coordinators, and supervisors in the youth shelter will be open to the idea of analyzing current programs and will present with honesty and truthfuness while completing the COPM and MODS. It is assumed that all parties involved have an interest in supporting this project with no other motive for supporting the researcher.

\section{AREAS FOR DEVELOPMENT}

An increased the data pool will allow for variability in different settings. There may be different barriers to OT intervention in different settings, affecting the role of OT to be defined. By carrying out all elements of this study in numerous shelters, the occupational performance and dysfunction findings would be drawn from a larger scale. In future studies a survey should be developed for the staff of the shelter to have recorded and sound evidence on what the role of OTs is in youth shelters. 